\title{
CATÁLOGO DE LOS MECÓPTEROS (INSECTA, MECOPTERA) DEL MUSEO NACIONAL DE CIENCIAS NATURALES (CSIC)
}

\author{
Irene Gómez-Undiano ${ }^{1} \&$ Mercedes París ${ }^{2, *}$ \\ ${ }^{1}$ Universidad Complutense de Madrid, Facultad de Ciencias Biológicas. Departamento de Biodiversidad, Ecología y Evolución. \\ C/ José Antonio Novais 12, 28040 Madrid (España). \\ Email: igomez04@ucm.es - ORCID iD: https://orcid.org/0000-0001-6100-0029 \\ ${ }^{2}$ Museo Nacional de Ciencias Naturales (CSIC), Colección de Entomología. C/ José Gutiérrez Abascal 2, 28006 Madrid (España). \\ Email: mercedes-paris@mncn.csic.es - ORCID iD: https://orcid.org/0000-0002-0161-7278 \\ *Autor para correspondencia: mercedes-paris@mncn.csic.es
}

\section{RESUMEN}

Se presenta un catálogo de la colección de mecópteros del Museo Nacional de Ciencias Naturales de Madrid (MNCN-CSIC), que reúne todo el material disponible desde finales del siglo XIX hasta las aportaciones más modernas. Se hace una revisión y con ello se aportan nuevos datos de localidades para la distribución conocida de las especies ibéricas.

Palabras clave: Panorpidae; Bittacidae; Bittacus aequalis; colecciones de Historia Natural.

\section{ABSTRACT} (CSIC)

Catalogue of mecopterans (Insecta, Mecoptera) in the Museo Nacional de Ciencias Naturales

A catalogue of the Mecoptera collection of the Museo Nacional de Ciencias Naturales of Madrid (MNCN-CSIC) is presented, gathering all the material available from the end of the $19^{\text {th }}$ century to the most modern accessions. A review is made and, thus, new data of localities for the known distribution of the lberian species are provided.

Key words: Panorpidae; Bittacidae; Bittacus aequalis; Natural History collections.

Recibido/Received: 10/02/2020; Aceptado/Accepted: 7/09/2020; Publicado en línea/Published online: 15/04/2021

Cómo citar este artículo/Citation: Gómez-Undiano, I. \& París, M. 2021. Catálogo de los mecópteros (Insecta, Mecoptera) del Museo Nacional de Ciencias Naturales (CSIC). Graellsia, 77(1): e123. https://doi.org/10.3989/graellsia.2021.v77.269

Copyright: ( 2021 SAM \& CSIC. Este es un artículo de acceso abierto distribuido bajo los términos de una licencia de uso y distribución Creative Commons Reconocimiento 4.0 Internacional (CC BY 4.0).

\section{Introducción}

Los mecópteros, también llamados moscas escorpión, son insectos holometábolos y están englobados en el superorden Mecopteroidea, junto a los dípteros y estrepsípteros (Grimaldi \& Engel, 2005). Según el registro fósil es el orden de insectos holometábolos más antiguo datado hasta la fecha (Carpenter, 1930; Willmann, 1987; Whiting, 2002), y comparte relación filogenética con los sifonápteros, dípteros y lepidópteros. Sin embargo, es uno de los órdenes de insectos menos estudiados y la mayor parte de las investigaciones actuales son estudios filogenéticos. Se conocen más de
600 especies a nivel mundial, teniendo en cuenta el registro fósil (Penny \& Byers, 1979; Novokshonov, 2004), de las cuales solo 5 especies, pertenecientes a 2 familias, se encuentran en la península ibérica (Monserrat \& Tillier, 2013). Las familias Bittacidae y Panorpidae contienen el $90 \%$ de las especies de mecópteros, siendo el género Panorpa Linnaeus, 1758, el que más especies posee (254 spp) (Whiting, 2002).

Los primeros estudios sobre la biología e identificación de especies paleárticas datan del siglo XIX y comienzos del XX, y la identificación está basada prácticamente en la morfología alar (p.ej., Klug, 1836; McLachlan, 1869). Durante el siglo XX, varios autores 
(Esben-Petersen, 1921; Hoffmann, 1966; Willmann, 1976; Ward, 1979) complementaron la identificación de especies con la morfología de la terminalia. Tillier (2008) propone una clave de identificación de las especies del género Panorpa de Francia, basada en caracteres tanto alares como de la genitalia.

En cuanto al conocimiento de la fauna ibérica, en 1903 se publica la primera monografía de los mecópteros ibéricos (Navás, 1903), recogiendo todas las citas y descripciones desde mediados del siglo XIX. Poco más de un siglo después, Monserrat \& Tillier (2013) publican una sinopsis de los mecópteros de la península ibérica donde recogen todos los ejemplares citados al revisar exhaustivamente la bibliografía publicada hasta la fecha. Además, estudian casi todo el material ibérico disponible, y aportan 721 nuevos registros, generando también unos mapas de distribución de las especies. Sin embargo, una de las colecciones que no fue consultada por Monserrat \& Tillier (2013) es la del Museo Nacional de Ciencias Naturales (MNCN-CSIC), la cual se revisa en este artículo con el objeto principal de dar a conocer el contenido de los fondos que conserva.

A finales del siglo $\mathrm{XX}$, según Izquierdo et al. (1997), en la Colección de Entomología del MNCN se conservaban 139 ejemplares, todos montados y preparados en seco, organizados en una única colección con ejemplares procedentes en su mayoría de la península ibérica. El 80\% de estos ejemplares están identificados y representan a 2 géneros y 7 especies, destacando además que incluye material tipo de un taxón descrito por L. Navás.

\section{Material y métodos}

La colección de mecópteros del MNCN no ha sido revisada recientemente, a diferencia de otros grupos. Se desconoce quién ordenó este material y cuándo, aunque es probable que fuese a mediados del siglo $X X$ y que se utilizasen solo caracteres de morfología alar para la clasificación de los ejemplares, por lo que, como ya comentan Monserrat \& Tillier (2013), algunos ejemplares estaban mal identificados.

Se ha revisado todo el material exhaustivamente con una lupa binocular, y su identificación ha sido realizada basándonos en los caracteres alares, y de terminalia en el caso de los machos, utilizando las claves de Tillier (2008) que recogen todas las especies ibéricas. Para los ejemplares de distribución neártica se emplearon las claves de Webb et al. (1975).

Todos los ejemplares han sido debidamente catalogados recogiendo toda la información que aportan las etiquetas. Algunas de estas carecían de información sobre legatario o determinador, pero en ocasiones estos datos se han podido deducir por la caligrafía. A cada ejemplar se le ha incorporado una etiqueta con su determinación y otra con un número de catálogo
MNCN Ent \#\#\#\#. Los datos de localidad del material ibérico se contrastaron con los de la literatura ya existente (i.e., Monserrat \& Tillier, 2013) y las bases de datos Biodiversidad Virtual (2019) y GBIF.org (2019).

En el transcurso de este trabajo se ha producido el ingreso en la Colección de Entomología de una cantidad importante de material conservado en etanol: 55 ejemplares entregados por el Dr. Mario García París, investigador del MNCN-CSIC, y otros 2 facilitados por la Dra. Carmen Rey del Castillo, entomóloga especialista en Hymenoptera Ichneumonidae.

\section{Resultados y discusión}

La colección cuenta en la actualidad con 209 ejemplares, que están conservados tanto en seco como en alcohol. Los ejemplares montados en seco suman un total de 150, al menos 20 de ellos fueron colectados a finales del siglo XIX (colección Seebold, colección Mazarredo Bolívar), siendo su procedencia principalmente francesa y española (Barcelona, Madrid y Vizcaya). Dado que muchos ejemplares carecen de fecha en su etiquetado, los periodos de colecta a partir del siglo $\mathrm{XX}$ se dedujeron basándonos tanto en las localidades como en los colectores, consultando además los datos disponibles de otros ejemplares de la Colección. De este modo, podemos hacernos una idea del número de individuos colectados durante los periodos 1901-1939, 1940-1965, 1966-2000 y 2001 hasta la actualidad. Con este criterio, y aunque algunos ejemplares no hemos podido asignarlos a un periodo concreto, alrededor del $65 \%$ del material fue colectado desde principios del siglo XX y antes de 1940 . Casi un 25\% fue recogido poco tiempo después, solo poco más del $5 \%$ se capturaría desde 1966 hasta final de siglo y apenas un 4\% se ha hecho durante el siglo XXI. Los colectores más activos fueron los Bolívar (Ignacio y Cándido) y los Martínez de la Escalera (Manuel y Fernando), destacando por otro lado el material colectado durante las expediciones del Instituto Español de Entomología. Por la letra manuscrita de las etiquetas deducimos que algunos de los ejemplares europeos llegaron a la colección debido a Longinos Navás, quien además fue prácticamente el único que, hasta ahora, había dejado etiquetas de identificación en alguno de los ejemplares.

Por el contrario, los ejemplares conservados en etanol corresponden casi en su totalidad a capturas realizadas durante el siglo XXI; como ya hemos comentado, el grueso de este material se debe a un reciente ingreso del Dr. Mario García París, y a dos ejemplares capturados con trampa Malaise por la Dra. Carmen Rey del Castillo. Los países representados en este material son España con 27 individuos, Francia con 14, Hungría con 7, Rumanía con 4, Japón con 3, e Italia con 2 y Portugal con 2.

Los ejemplares de la colección pertenecen a 2 familias y 10 especies (Tabla 1), una de ellas identificada 
Tabla 1.- Número de ejemplares de la colección de mecópteros del MNCN (CSIC) para cada especie, según áreas biogeográficas. $\mathrm{lb}$. = lbérica; Pal. = Paleártica; Nea. = Neártica; Afr. = Afrotropical.

Table 1.- Number of specimens of the MNCN mecopters collection (CSIC) for each species, according to biogeographical areas. lb. $=$ lberian; Pal. $=$ Palearctic; Nea. $=$ Nearctic; Afr. $=$ Afrotropical.

\begin{tabular}{|c|c|c|c|c|c|c|}
\hline \multirow[b]{2}{*}{ FAMILIA } & \multirow[b]{2}{*}{ ESPECIE } & \multicolumn{4}{|c|}{ ÁREAS BIOGEOGRÁFICAS } & \multirow[b]{2}{*}{ TOTAL } \\
\hline & & Ib. & Pal. & Nea. & Afr. & \\
\hline \multirow[t]{2}{*}{ Bittacidae } & Bittacus aequalis Navás, 1914 & & & & 1 & 1 \\
\hline & Bittacus italicus (Allioni, 1766) & 1 & 1 & & & 2 \\
\hline \multirow[t]{8}{*}{ Panorpidae } & Panorpa alpina Rambur, 1842 & & 4 & & & 4 \\
\hline & Panorpa cognata Rambur, 1842 & & 3 & & & 3 \\
\hline & Panorpa communis Linnaeus, 1758 & 13 & 10 & & & 23 \\
\hline & Panorpa germanica Linnaeus, 1758 & 6 & 10 & & & 16 \\
\hline & Panorpa meridionalis Rambur, 1842 & 128 & 23 & & & 151 \\
\hline & Panorpa rufescens Rambur, 1842 & & & 2 & & 2 \\
\hline & Panorpa vulgaris Imhoff \& Labram, 1845 & 1 & 3 & & & 4 \\
\hline & Panorpa Linnaeus, 1758 & & 3 & & & 3 \\
\hline
\end{tabular}

solo a nivel de género. Aunque la mayoría de los ejemplares proceden de la península ibérica, también hay varios registros paleárticos no ibéricos, pertenecientes a especies que habitan la Península o que potencialmente pueden hacerlo (Monserrat \& Tillier, 2013).

De la familia Bittacidae hay dos especies representadas en la colección:
- Bittacus italicus (Allioni, 1766) (Fig. 1), especie de distribución paleártica, incluida la península ibérica. Se han localizado dos ejemplares, uno de Francia y otro de España, éste último procedente de una colecta de Navás. En toda la bibliografía consultada se indica a Müller como autor de la especie Bittacus italicus, pero nuestro colega el Dr. Alonso Zarazaga

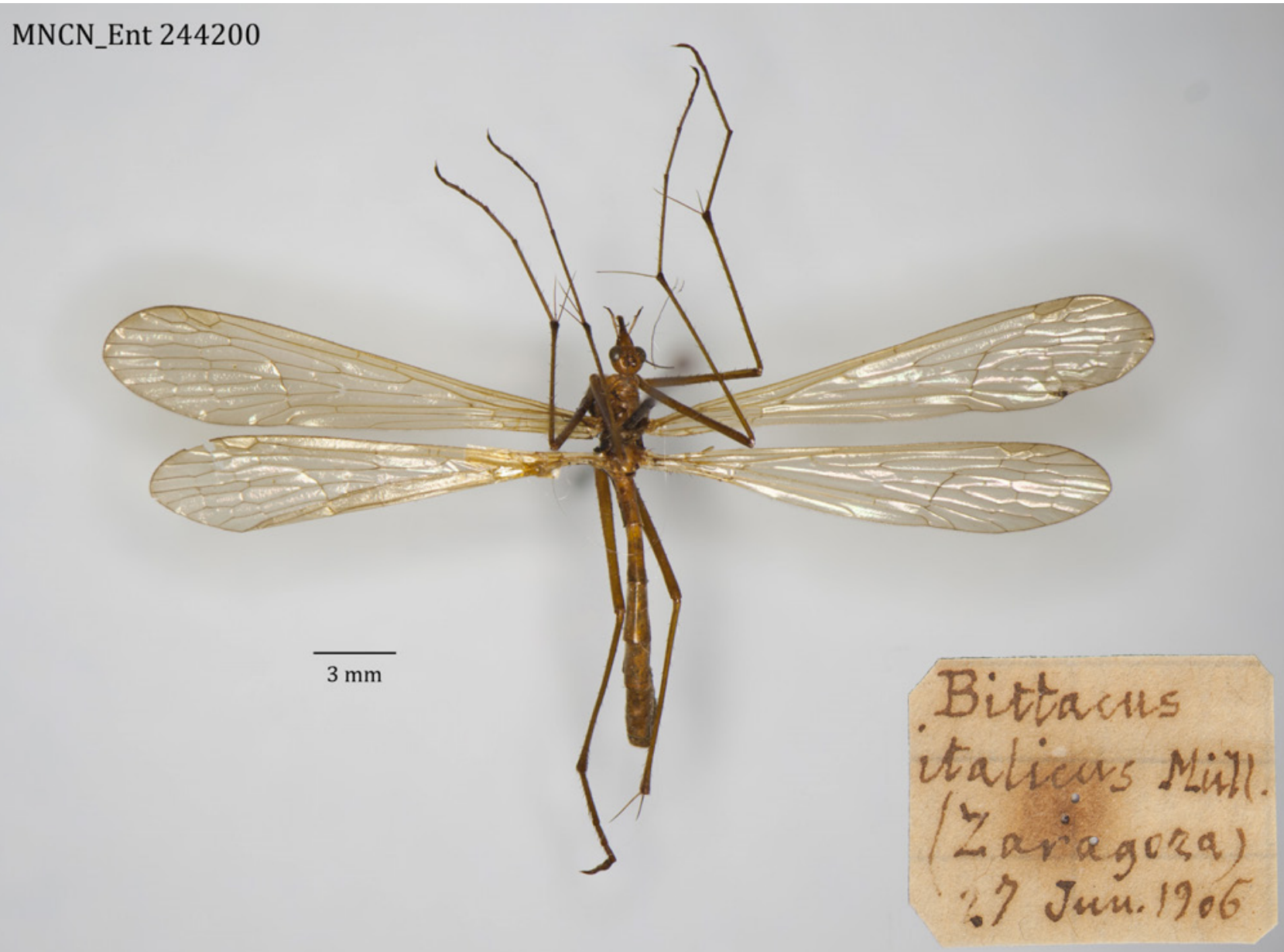

Fig. 1.- Bittacus italicus (Allioni, 1766). Habitus y etiquetado del ejemplar MNCN_Ent 244200.

Fig. 1.-Bittacus italicus (Allioni, 1766). Habitus and label of the specimen MNCN_Ent 244200. 
(com. pers.) nos ha hecho notar que es Carlo Allioni (1766) quien hace la descripción de la especie, pues éste indica en la introducción de su trabajo que ha recibido una lista de insectos capturados en los alrededores de Turín y que él la ha completado con descripciones.

- Bittacus aequalis Navás, 1914 (Fig. 2), especie de distribución afrotropical que cuenta con un único ejemplar colectado durante la expedición científica de Ch. Alluaud y R. Jeannel en el África Oriental entre 1911 y 1912. Este ejemplar está etiquetado como "COTYPE”.

De la familia Panorpidae hay 8 especies representadas en la colección:

- Panorpa alpina Rambur, 1842 (Fig. 3) y Panorpa cognata Rambur, 1842 (Fig. 4) están representadas en la colección en seco, cada una por tres ejemplares europeos, probablemente en su mayoría facilitados por Longinos Navás. Entre el material conservado en alcohol hay un ejemplar de $P$. alpina colectado en Rumanía. No existe material ibérico, pero su presencia en la Península es posible, aunque no está confirmada.

- Panorpa communis Linnaeus, 1758 (Fig. 5) y Panorpa germanica Linnaeus, 1758 (Fig. 6) son es- pecies con distribuciones paleárticas, incluida la península ibérica. En esta colección, la primera especie está representada tanto por ejemplares españoles de las provincias de A Coruña, Asturias, Cantabria, Girona, Huesca, León, Navarra y Pontevedra, como por ejemplares de otros países como Francia, Hungría, Italia y Rumanía. El material más antiguo de esta especie, procedente de colectas probablemente anteriores a 1966, es exclusivamente español, mientras que el material de más reciente ingreso procede de España y de los países mencionados. Panorpa germanica está representada por ejemplares de Bélgica, España, Francia, Italia y Rumanía. El material europeo más antiguo, conservado en seco, está relacionado con las colecciones de Navás y Seebold, salvo un ejemplar italiano colectado por Cándido Bolívar en 1930. El material de Rumanía es moderno y está conservado en alcohol. Los ejemplares españoles están todos conservados en seco, y provienen de Bilbao (colección Seebold), y de la colecta o colectas de Ignacio Bolívar en Puente Viesgo (Cantabria).

- Panorpa meridionalis Rambur, 1842 (Fig. 7) es la especie mejor representada en la colección (151 ejemplares), debido a que es la especie de mecóptero más

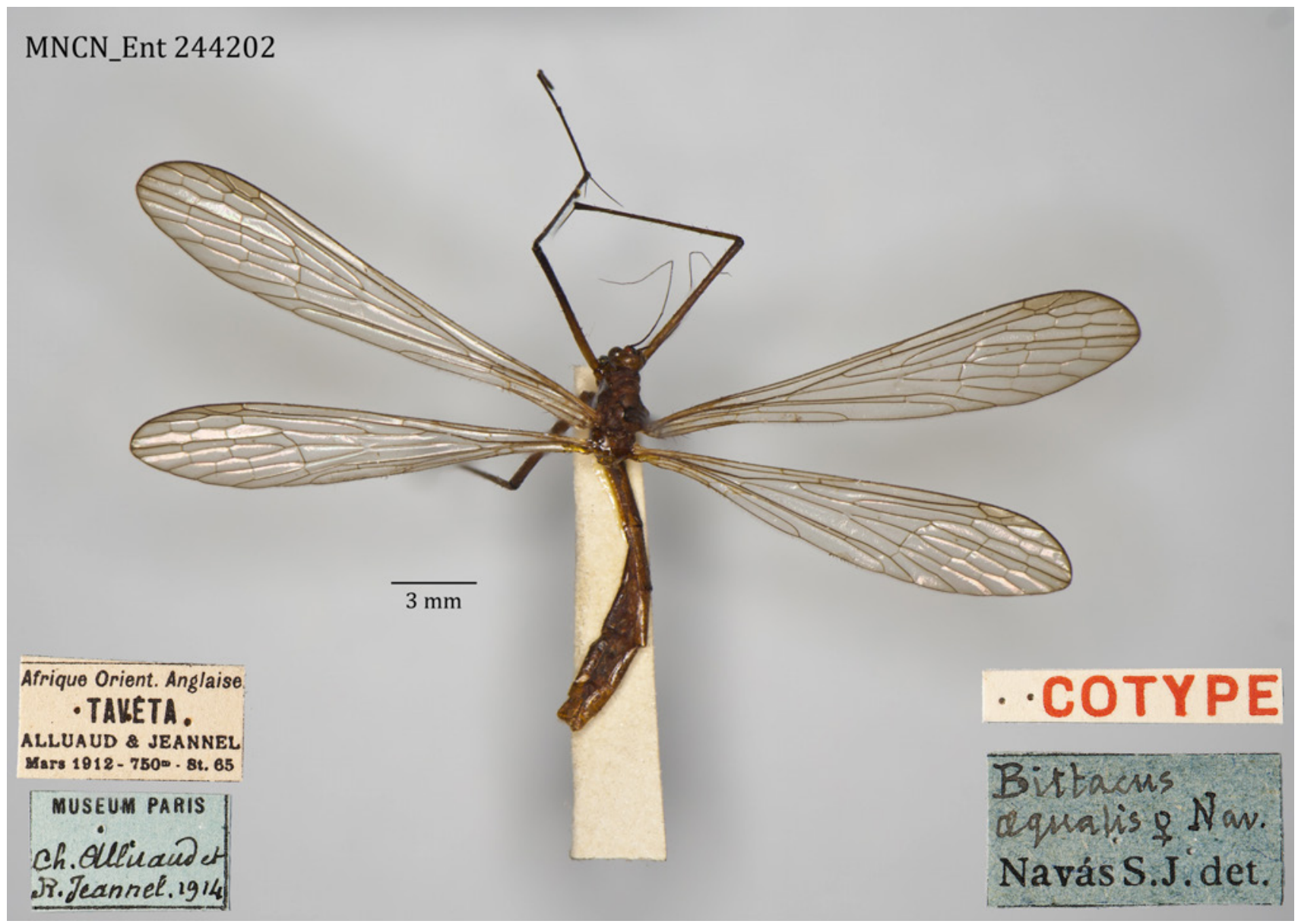

Fig. 2.-Bittacus aequalis Navás, 1914. Habitus y etiquetado del ejemplar MNCN_Ent 244202.

Fig. 2.-Bittacus aequalis Navás, 1914. Habitus and labels of the specimen MNCN_Ent 244202. 


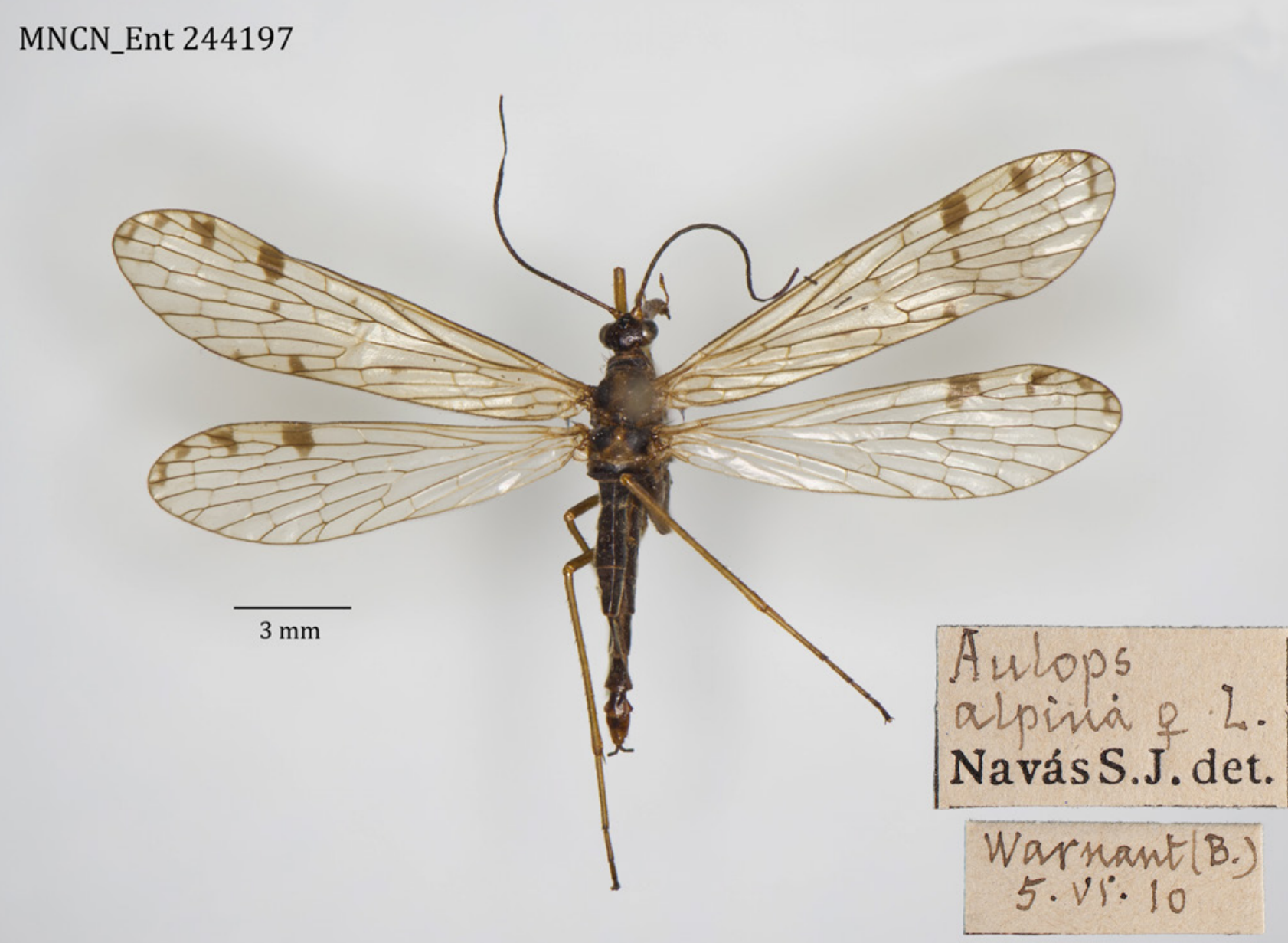

Fig. 3.- Panorpa alpina Rambur, 1842. Habitus y etiquetado del ejemplar MNCN_Ent 244197 Fig. 3.- Panorpa alpina Rambur, 1842. Habitus and labels of the specimen MNCN_Ent 244197

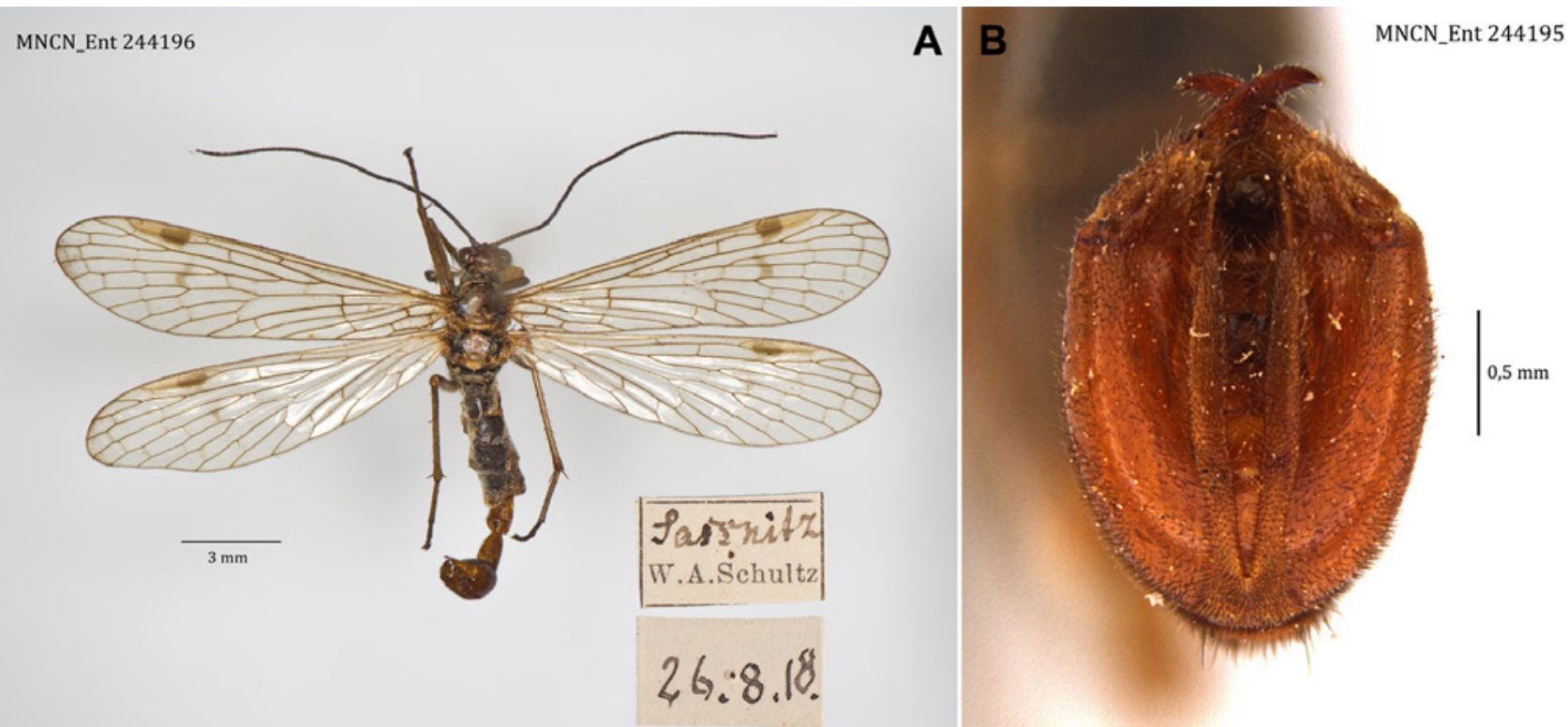

Fig. 4.- Panorpa cognata Rambur, 1842. A. Habitus y etiquetado del ejemplar MNCN_Ent 244196. B. Genitalia masculina del ejemplar MNCN_Ent 244195.

Fig. 4.- Panorpa cognata Rambur, 1842. A. Habitus and labels of the specimen MNCN_Ent 244196. B. Male genitalia of the specimen MNCN_Ent 244195. 


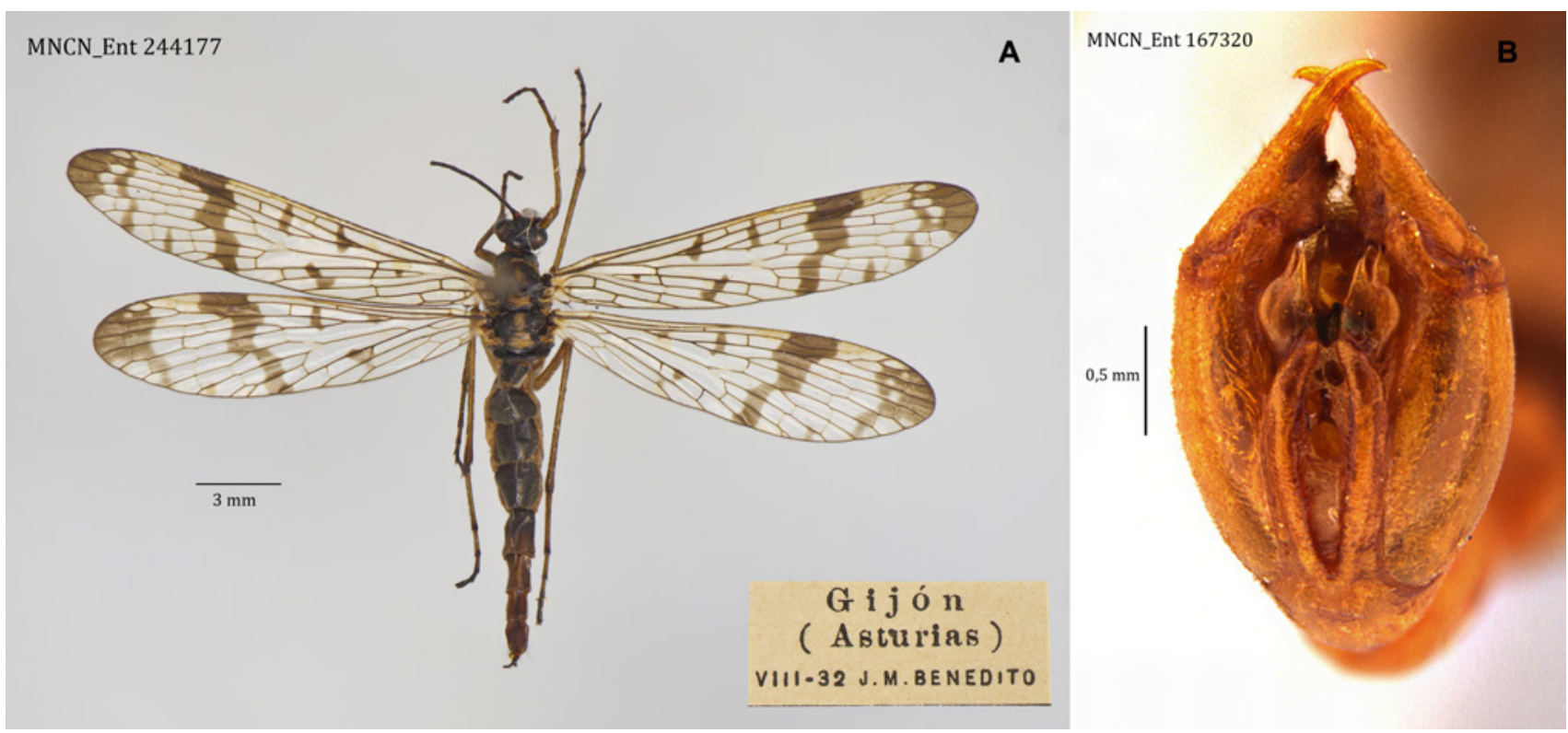

Fig. 5.- Panorpa communis Linnaeus, 1758. A. Habitus y etiquetado del ejemplar MNCN_Ent 244177. B. Genitalia del ejemplar MNCN_Ent 167320.

Fig. 5.- Panorpa communis Linnaeus, 1758. A. Habitus and labels of the specimen MNCN_Ent 244177. B. Genitalia of the specimen MNCN_Ent 167320.

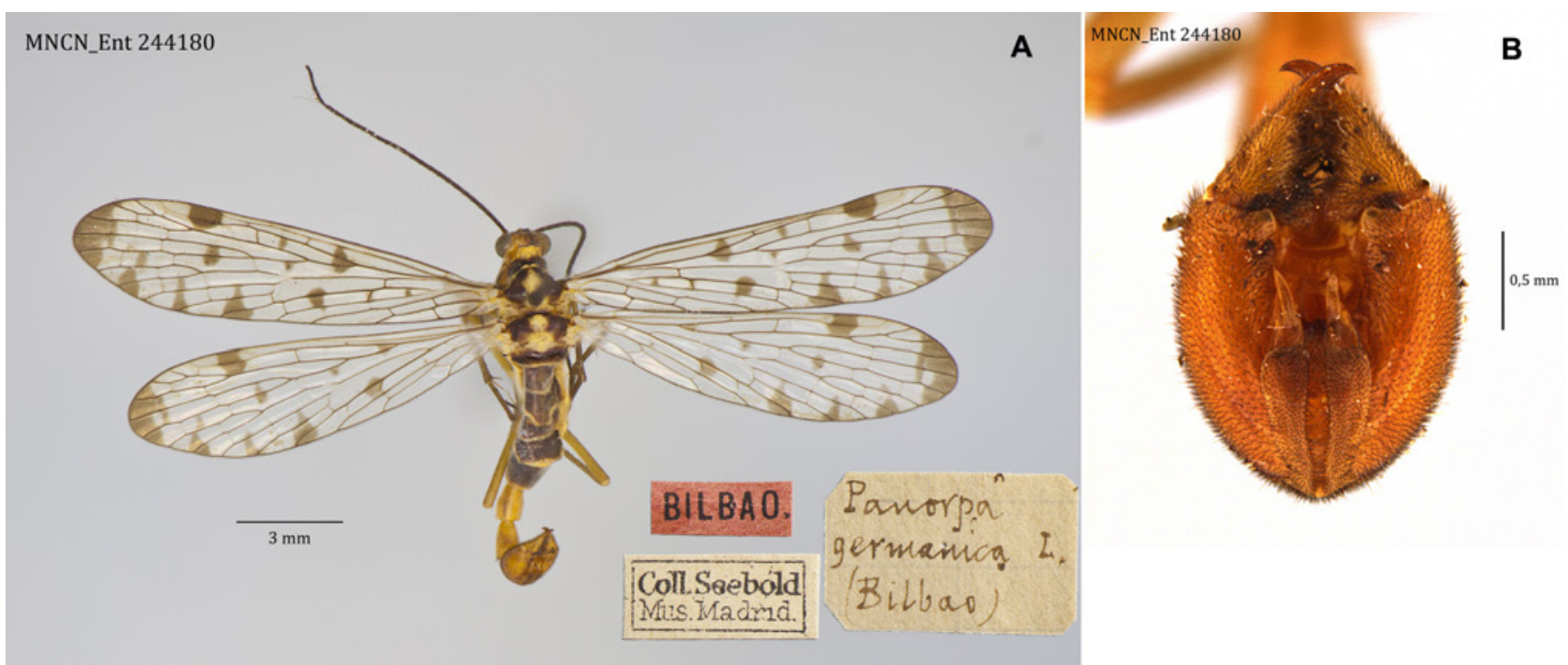

Fig. 6.- Panorpa germanica Linnaeus, 1758, ejemplar MNCN_Ent 244180. A. Habitus y etiquetado. B. Genitalia.

Fig. 6.- Panorpa germanica Linnaeus, 1758, specimen MNCN_Ent 244180. A. Habitus and label. B. Genitalia.

común en el territorio ibérico. Aparte de este material ibérico (Tabla 1), en la colección hay algunos ejemplares del resto de Europa: Bélgica, Francia y Suiza, que proceden tanto de materiales de Seebold y Navás, los más antiguos, como de recientes ingresos.

- Panorpa rufescens Rambur, 1842 (Fig. 8) está representada en la colección por dos ejemplares que fueron colectados en Ithaca, Nueva York, Estados Unidos, por Cándido Bolívar, durante su asistencia al IV Congreso Internacional de Entomología celebrado en la Universidad de Cornell, en agosto de 1928. No se habían identificado hasta el presente trabajo.

- Panorpa vulgaris Imhoff \& Labram, 1845 está representada en la colección exclusivamente por cuatro ejemplares conservados en alcohol, que han sido recolectados en España, Francia y Hungría.

- Panorpa Linnaeus, 1758 son ejemplares conservados en etanol, colectados en Japón, que no han podido ser identificados a nivel de especie debido a la falta de disponibilidad de bibliografía actual y completa. 

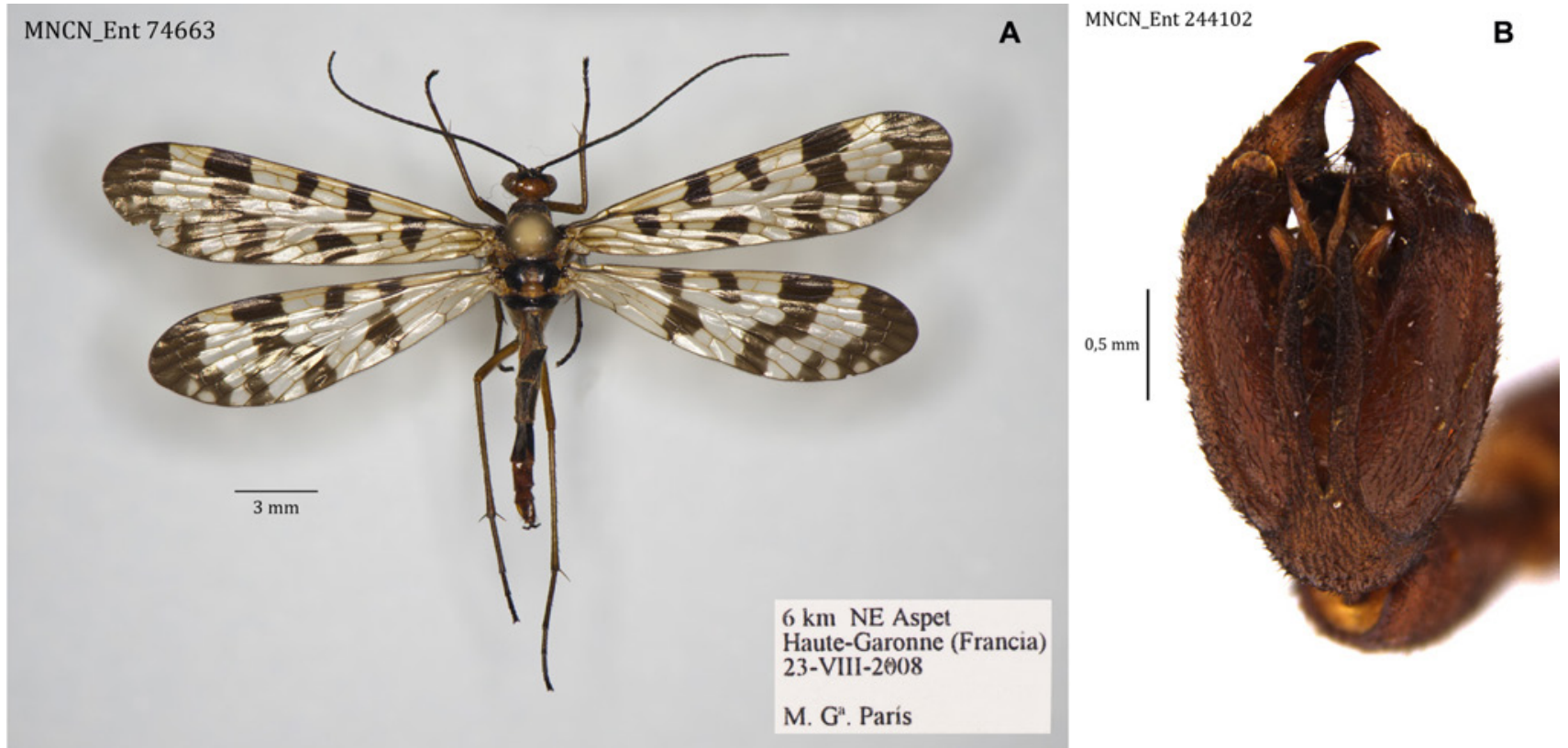

Fig. 7.- Panorpa meridionalis Rambur, 1842. A. Habitus y etiquetado del ejemplar MNCN_Ent 74663. B. Genitalia del ejemplar MNCN_Ent 244102.

Fig. 7.- Panorpa meridionalis Rambur, 1842. A. Habitus and label of the specimen MNCN_Ent 74663. B. Genitalia of the specimen MNCN_Ent 244102.

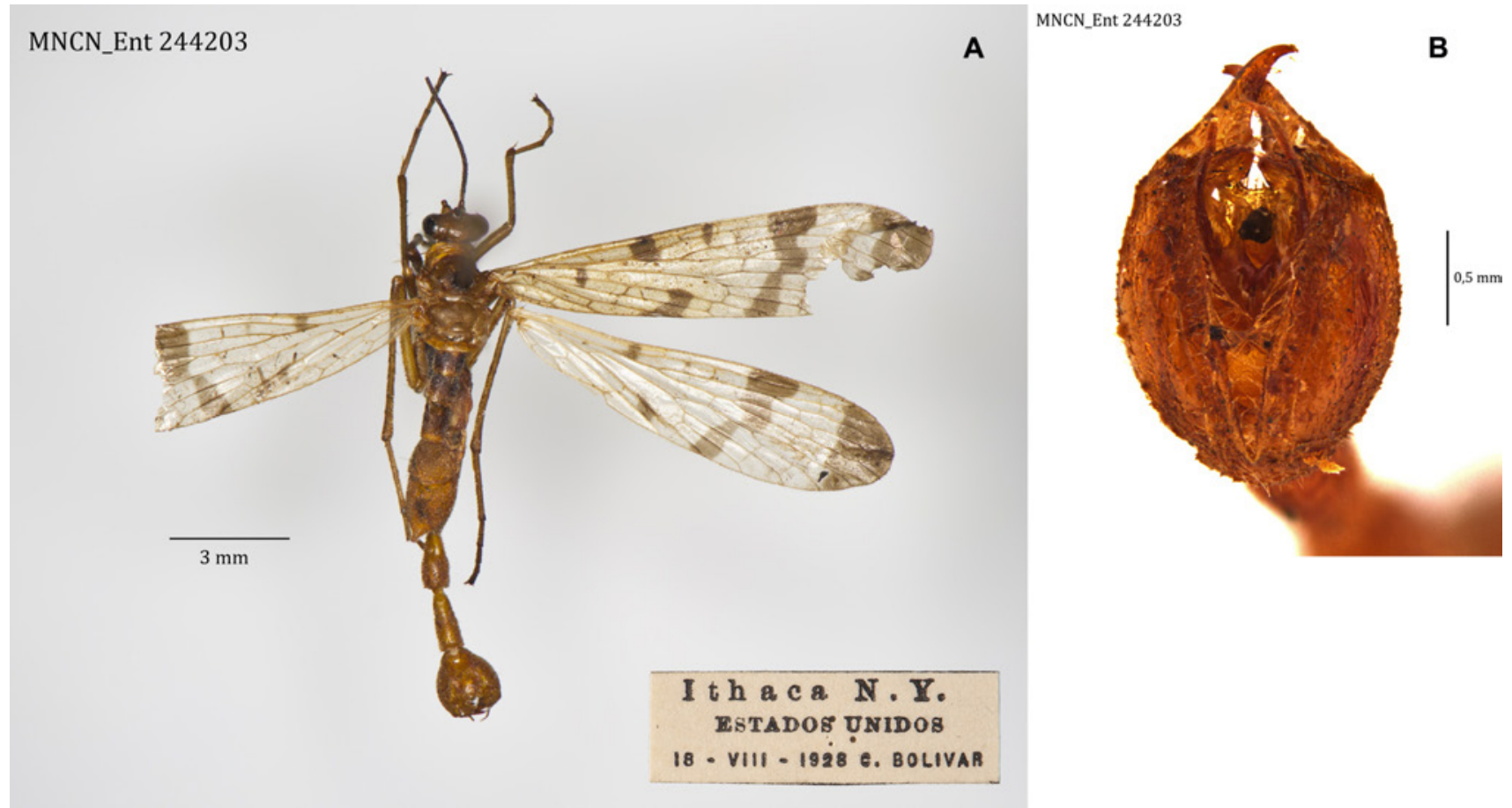

Fig. 8.- Panorpa rufescens Rambur, 1842, ejemplar MNCN_Ent 244203. A. Habitus y etiquetado. B. Genitalia.

Fig. 8._- Panorpa rufescens Rambur, 1842, specimen MNCN_Ent 244203. A. Habitus and label. B. Genitalia.

En la Tabla 2 se listan todos los ejemplares de la colección de mecópteros ordenados por familia y especie, y se incluyen los datos de las etiquetas de captura, el número de catálogo, la procedencia, altitud si figura en el etiquetado, sexo y algunas observaciones, señalándose en esta columna los individuos que aportan nuevos datos de localidad para la fauna ibérica. Se considera nueva localidad aquella que aporta una nueva cuadrícula UTM de $10 \times 10 \mathrm{~km}$ a la distribución conocida hasta la fecha. 
Tabla 2.- Catálogo de la colección de Mecoptera del MNCN-CSIC. Los datos de la etiqueta de captura figuran como "país: provincia: localidad, fecha de colecta. Colector." En el caso de que faltase alguno, es especificado. Los datos entre corchetes son aclaraciones o interpretaciones de las autoras.

Table 2.- Catalogue of the MNCN-CSIC Mecoptera collection. The information on the collecting label appears as "country: province: locality, date of collection. Collector.", and if one is missing, it is specified. The data in square brackets are clarifications or interpretations.

\begin{tabular}{|c|c|c|c|c|c|c|c|c|}
\hline FAMILIA & ESPECIE & DATOS DE CAPTURA & No CAT. & PROCEDENCIA & ALTITUD & SEXO & OBSERVACIONES & DETERMINADO \\
\hline \multirow[t]{3}{*}{ BITTACIDAE } & $\begin{array}{l}\text { Bittacus } \\
\text { aequalis } \\
\text { Navás, } 1914\end{array}$ & $\begin{array}{l}\text { Kenia: Taita-Taveta: } \\
\text { Afrique Orient. Anglaise, } \\
\text { Taveta, Mars } 1912 \text {. } \\
\text { Alluaud \& Jeannel. } \\
\text { St. } 65\end{array}$ & $\begin{array}{l}\text { MNCN Ent } \\
24420 \overline{2}\end{array}$ & $\begin{array}{l}\text { Museum Paris, } \\
\text { Alluaud et } \\
\text { Jeannel, } 1914\end{array}$ & $750 \mathrm{~m}$ & Hembra & $\begin{array}{l}\text { Etiquetas: Cotype // Bittacus aequalis } q \\
\text { Nav. Navás S.J. det. No pertenece a la } \\
\text { serie tipo; en la descripción Navás habla } \\
\text { de macho exclusivamente. La localidad } \\
\text { es Landjoro, } 900 \text { m. y la sigla St. } 64\end{array}$ & Navás S.J., det. \\
\hline & $\begin{array}{l}\text { Bittacus } \\
\text { italicus } \\
\text { (Allioni, 1766) }\end{array}$ & $\begin{array}{l}\text { España: Zaragoza: } \\
\text { (Zaragoza), } 7 \text { Jun } 1906 . \\
\text { [Navás] }\end{array}$ & $\begin{array}{l}\text { MNCN Ent } \\
244200\end{array}$ & & & & $\begin{array}{l}\text { Etiqueta: Bittacus italicus Müll. } \\
\text { (Zaragoza) } 27 \text { Jun } 1906 \text { [manuscrita, } \\
\text { aparentemente de Navás] }\end{array}$ & $\begin{array}{l}\text { I.G. Undiano, } \\
2019 \text { det. }\end{array}$ \\
\hline & & $\begin{array}{l}\text { Francia: Alpes- } \\
\text { Maritimes: Brigue, sin } \\
\text { datos. sin datos }\end{array}$ & $\begin{array}{l}\text { MNCN Ent } \\
24420 \overline{1}\end{array}$ & & & Macho & & $\begin{array}{l}\text { I.G. Undiano, } \\
2019 \text { det. }\end{array}$ \\
\hline \multirow[t]{18}{*}{ PANORPIDAE } & $\begin{array}{l}\text { Panorpa } \\
\text { alpina } \\
\text { Rambur, } 1842\end{array}$ & $\begin{array}{l}\text { Austria: Salzburgo: } \\
\text { Gastein, Austria, sin } \\
\text { datos. sin datos }\end{array}$ & $\begin{array}{l}\text { MNCN Ent } \\
24419 \overline{8}\end{array}$ & & & Hembra & & $\begin{array}{l}\text { I.G. Undiano, } \\
2019 \text { det. }\end{array}$ \\
\hline & & $\begin{array}{l}\text { Austria: Salzburgo: } \\
\text { Gastein, Austria, sin } \\
\text { datos. sin datos }\end{array}$ & $\begin{array}{l}\text { MNCN Ent } \\
244199\end{array}$ & & & Hembra & Etiqueta con número 144. & $\begin{array}{l}\text { I.G. Undiano, } \\
2019 \text { det. }\end{array}$ \\
\hline & & $\begin{array}{l}\text { Bélgica: Namur: } \\
\text { Warnant (B.), 5-Vl-10. } \\
\text { [Navás] }\end{array}$ & $\begin{array}{l}\text { MNCN Ent } \\
24419 \overline{7}\end{array}$ & & & Hembra & $\begin{array}{l}\text { Etiqueta: Aulops alpina } q \text { L. Navás } \\
\text { S.J. det. }\end{array}$ & $\begin{array}{l}\text { I.G. Undiano, } \\
2019 \text { det. }\end{array}$ \\
\hline & & $\begin{array}{l}\text { Rumania: Cluj: Lacul } \\
\text { Tarnita, 21-VIl-2011. M. } \\
\text { GaParís, J. Vörös }\end{array}$ & $\begin{array}{l}\text { MNCN_Ent } \\
25496 \overline{9}\end{array}$ & & $600 \mathrm{~m}$. & Hembra & Alcohol & $\begin{array}{l}\text { I.G. Undiano, } \\
2019 \text { det. }\end{array}$ \\
\hline & $\begin{array}{l}\text { Panorpa } \\
\text { cognata } \\
\text { Rambur, } 1842\end{array}$ & $\begin{array}{l}\text { Alemania: Mecklemburgo- } \\
\text { Pomerania Occidental: } \\
\text { Saßnitz, 26-8-18. W. A. } \\
\text { Schultz }\end{array}$ & $\begin{array}{l}\text { MNCN Ent } \\
244196\end{array}$ & & & Macho & & $\begin{array}{l}\text { I.G. Undiano, } \\
2019 \text { det. }\end{array}$ \\
\hline & & $\begin{array}{l}\text { Bélgica: Namur: Bocq } \\
\text { (Belg.), 31-VIII-10. [Navás] }\end{array}$ & $\begin{array}{l}\text { MNCN Ent } \\
24419 \overline{5}\end{array}$ & & & Macho & $\begin{array}{l}\text { Etiqueta: Panorpa cognata Ramb. Navás } \\
\text { S.J. det. }\end{array}$ & $\begin{array}{l}\text { I.G. Undiano, } \\
2019 \text { det. }\end{array}$ \\
\hline & & $\begin{array}{l}\text { Bélgica: Namur: } \\
\text { Warnant (B.), 7-VIII-10. } \\
\text { [Navás] }\end{array}$ & $\begin{array}{l}\text { MNCN Ent } \\
24419 \overline{4}\end{array}$ & & & Hembra & $\begin{array}{l}\text { Etiqueta: Panorpa cognata } q \text { Rb. Navás } \\
\text { S.J. det. }\end{array}$ & $\begin{array}{l}\text { I.G. Undiano, } \\
2019 \text { det. }\end{array}$ \\
\hline & $\begin{array}{l}\text { Panorpa } \\
\text { communis } \\
\text { Linnaeus, } \\
1758\end{array}$ & $\begin{array}{l}\text { España: A Coruña: } \\
\text { Pontedeume: Monte } \\
\text { Breamo, 28-IV-2010. } \\
\text { M. GaParis }\end{array}$ & $\begin{array}{l}\text { MNCN Ent } \\
25498 \overline{7}\end{array}$ & & & Hembra & Alcohol, nuevo dato de localidad & $\begin{array}{l}\text { I.G. Undiano, } \\
2019 \operatorname{det}\end{array}$ \\
\hline & & $\begin{array}{l}\text { España: Asturias: Alto } \\
\text { del Torno, 19-VII-2010. } \\
\text { J.G. Rodriguez }\end{array}$ & $\begin{array}{l}\text { MNCN Ent } \\
254994\end{array}$ & & & Macho & Alcohol & $\begin{array}{l}\text { I.G. Undiano, } \\
2019 \text { det. }\end{array}$ \\
\hline & & $\begin{array}{l}\text { España: Asturias: Giijón } \\
\text { (Asturias), VIII-32. J. M. } \\
\text { Benedito }\end{array}$ & $\begin{array}{l}\text { MNCN Ent } \\
24417 \overline{7}\end{array}$ & & & Hembra & & $\begin{array}{l}\text { I.G. Undiano, } \\
2019 \text { det. }\end{array}$ \\
\hline & & $\begin{array}{l}\text { España: Cantabria: } \\
\text { Toñanes, 17/06/1998. } \\
\text { M.G. Paris }\end{array}$ & $\begin{array}{l}\text { MNCN_Ent } \\
75336\end{array}$ & & & Macho & Alcohol, nuevo dato de localidad & $\begin{array}{l}\text { I.G. Undiano, } \\
2019 \text { det }\end{array}$ \\
\hline & & $\begin{array}{l}\text { España: Cantabria: } \\
\text { Monte Corona, } \\
\text { 05/07/1998. M.G. Paris }\end{array}$ & $\begin{array}{l}\text { MNCN_Ent } \\
75337\end{array}$ & & & Hembra & Alcohol, nuevo dato de localidad & $\begin{array}{l}\text { I.G. Undiano, } \\
2019 \text { det }\end{array}$ \\
\hline & & $\begin{array}{l}\text { España: Girona: Santa } \\
\text { Coloma de Farnés, } 26- \\
\text { VI-2009. J.G. Rodríguez }\end{array}$ & $\begin{array}{l}\text { MNCN Ent } \\
25499 \overline{9}\end{array}$ & & & Macho & Alcohol, nuevo dato de localidad & $\begin{array}{l}\text { I.G. Undiano, } \\
2019 \text { det }\end{array}$ \\
\hline & & $\begin{array}{l}\text { España: Huesca: } \\
\text { Panticosa, Prov. de } \\
\text { Huesca, 10-18-43. M. } \\
\text { Bohigas }\end{array}$ & $\begin{array}{l}\text { MNCN Ent } \\
24417 \overline{5}\end{array}$ & & $1.800 \mathrm{~m}$. & Hembra & nuevo dato de localidad & $\begin{array}{l}\text { I.G. Undiano, } \\
2019 \text { det. }\end{array}$ \\
\hline & & $\begin{array}{l}\text { España: Huesca: } \\
\text { Panticosa, sin datos. } \\
\text { sin datos }\end{array}$ & $\begin{array}{l}\text { MNCN_Ent } \\
167320\end{array}$ & Exposición IEE & $1.300 \mathrm{~m}$. & Macho & nuevo dato de localidad & $\begin{array}{l}\text { I.G. Undiano, } \\
2019 \text { det. }\end{array}$ \\
\hline & & $\begin{array}{l}\text { España: Huesca: } \\
\text { Panticosa, sin datos. } \\
\text { sin datos }\end{array}$ & $\begin{array}{l}\text { MNCN Ent } \\
24417 \overline{4}\end{array}$ & & $1.300 \mathrm{~m}$. & Hembra & nuevo dato de localidad & $\begin{array}{l}\text { I.G. Undiano, } \\
2019 \text { det. }\end{array}$ \\
\hline & & $\begin{array}{l}\text { España: León: Villablino } \\
\text { (León), VII-50. sin datos }\end{array}$ & $\begin{array}{l}\text { MNCN Ent } \\
24417 \overline{8}\end{array}$ & & $1.000 \mathrm{~m}$. & & nuevo dato de localidad & $\begin{array}{l}\text { I.G. Undiano, } \\
2019 \text { det. }\end{array}$ \\
\hline & & $\begin{array}{l}\text { España: León: Villablino } \\
\text { (León), 10-13-VIII-941. } \\
\text { J. Abajo }\end{array}$ & $\begin{array}{l}\text { MNCN_Ent } \\
24417 \overline{9}\end{array}$ & & $1.000 \mathrm{~m}$. & Hembra & nuevo dato de localidad & $\begin{array}{l}\text { I.G. Undiano, } \\
2019 \text { det. }\end{array}$ \\
\hline
\end{tabular}




\begin{tabular}{|c|c|c|c|c|c|c|c|c|}
\hline FAMILIA & ESPECIE & DATOS DE CAPTURA & $\mathrm{N}^{\circ}$ CAT. & PROCEDENCIA & ALTITUD & SEXO & OBSERVACIONES & DETERMINADO \\
\hline \multirow[t]{18}{*}{ PANORPIDAE } & $\begin{array}{l}\text { Panorpa } \\
\text { communis } \\
\text { Linnaeus, } \\
1758\end{array}$ & $\begin{array}{l}\text { España: Navarra: } \\
\text { Elizondo, Valle del } \\
\text { Baztán, Prov. de } \\
\text { Navarra, sin datos. sin } \\
\text { datos }\end{array}$ & $\begin{array}{l}\text { MNCN_Ent } \\
24417 \overline{6}\end{array}$ & & & Hembra & & $\begin{array}{l}\text { I.G. Undiano, } \\
2019 \text { det. }\end{array}$ \\
\hline & & $\begin{array}{l}\text { España: Pontevedra: } \\
\text { Catoira, 14-VI-2018. R. } \\
\text { González }\end{array}$ & $\begin{array}{l}\text { MNCN_Ent } \\
254979\end{array}$ & & & Hembra & Alcohol, nuevo dato de localidad & $\begin{array}{l}\text { I.G. Undiano, } \\
2019 \text { det }\end{array}$ \\
\hline & & $\begin{array}{l}\text { Francia: Haute- } \\
\text { Garonne: Le Mourtis, } \\
\text { 26-VIII-2008. M. } \\
\text { GParís, N.P. Daniel, } \\
\text { G.G. Martín }\end{array}$ & $\begin{array}{l}\text { MNCN_Ent } \\
254988\end{array}$ & & & Hembra & Alcohol & $\begin{array}{l}\text { I.G. Undiano, } \\
2019 \text { det }\end{array}$ \\
\hline & & $\begin{array}{l}\text { Francia: Haute- } \\
\text { Garonne: Plan du } \\
\text { Rey, 26-VIII-2008. M. } \\
\text { GaParís, N.P. Daniel, } \\
\text { G.G. Martín }\end{array}$ & $\begin{array}{l}\text { MNCN_Ent } \\
25498 \overline{6}\end{array}$ & & & Hembra & Alcohol & $\begin{array}{l}\text { I.G. Undiano, } \\
2019 \text { det }\end{array}$ \\
\hline & & $\begin{array}{l}\text { Hungria: Veszprém: } \\
\text { Németbánya, 16-VII- } \\
\text { 2011. M. GaParís, J. } \\
\text { Vörös }\end{array}$ & $\begin{array}{l}\text { MNCN_Ent } \\
254961\end{array}$ & & $344 \mathrm{~m}$. & Macho & Alcohol & $\begin{array}{l}\text { I.G. Undiano, } \\
2019 \text { det }\end{array}$ \\
\hline & & $\begin{array}{l}\text { Hungria: Veszprém: } \\
\text { Németbánya, 16-VII- } \\
\text { 2011. M. GaParís, J. } \\
\text { Vörös }\end{array}$ & $\begin{array}{l}\text { MNCN_Ent } \\
254962\end{array}$ & & $344 \mathrm{~m}$. & Macho & Alcohol & $\begin{array}{l}\text { I.G. Undiano, } \\
2019 \text { det }\end{array}$ \\
\hline & & $\begin{array}{l}\text { Hungria: Veszprém: } \\
\text { Németbánya, 16-VII- } \\
\text { 2011. M. GaParís, J. } \\
\text { Vörös }\end{array}$ & $\begin{array}{l}\text { MNCN_Ent } \\
25496 \overline{3}\end{array}$ & & $344 \mathrm{~m}$. & Hembra & Alcohol & $\begin{array}{l}\text { I.G. Undiano, } \\
2019 \text { det }\end{array}$ \\
\hline & & $\begin{array}{l}\text { Hungria: Veszprém: } \\
\text { Németbánya, 16-VII- } \\
\text { 2011. M. Ga'Paris, J. } \\
\text { Vörös }\end{array}$ & $\begin{array}{l}\text { MNCN_Ent } \\
254965\end{array}$ & & $344 \mathrm{~m}$. & Hembra & Alcohol & $\begin{array}{l}\text { I.G. Undiano, } \\
2019 \text { det }\end{array}$ \\
\hline & & $\begin{array}{l}\text { Hungria: Veszprém: } \\
\text { Németbánya, 16-VII- } \\
\text { 2011. M. Ga'Paris, J. } \\
\text { Vörös }\end{array}$ & $\begin{array}{l}\text { MNCN_Ent } \\
254971\end{array}$ & & $344 \mathrm{~m}$. & Hembra & Alcohol & $\begin{array}{l}\text { I.G. Undiano, } \\
2019 \text { det }\end{array}$ \\
\hline & & $\begin{array}{l}\text { Italia: Valle d'Aosta: } \\
\text { Cogne: Valnontey, } \\
\text { 29-VI-2012. M. G'París, } \\
\text { J. Vörös }\end{array}$ & $\begin{array}{l}\text { MNCN_Ent } \\
25497 \overline{7}\end{array}$ & & $1.692 \mathrm{~m}$. & Hembra & Alcohol & $\begin{array}{l}\text { I.G. Undiano, } \\
2019 \text { det }\end{array}$ \\
\hline & & $\begin{array}{l}\text { Italia: Valle d'Aosta: } \\
\text { Valgrisenche: Planaval, } \\
\text { 29-VI-2012. M. GaParís, } \\
\text { J. Vörös }\end{array}$ & $\begin{array}{l}\text { MNCN_Ent } \\
254976\end{array}$ & & $1.527 \mathrm{~m}$ & Hembra & Alcohol & $\begin{array}{l}\text { I.G. Undiano, } \\
2019 \text { det }\end{array}$ \\
\hline & & $\begin{array}{l}\text { Rumanía: Alba: } 2 \text { km } \\
\text { SO Valea Larga (hasta } \\
\text { Ponor), 20-VII-2011. M. } \\
\text { GaParís, J. Vörös }\end{array}$ & $\begin{array}{l}\text { MNCN_Ent } \\
254967\end{array}$ & & $841 \mathrm{~m}$. & Macho & Alcohol & $\begin{array}{l}\text { I.G. Undiano, } \\
2019 \text { det }\end{array}$ \\
\hline & \multirow{6}{*}{$\begin{array}{l}\text { Panorpa } \\
\text { germanica } \\
\text { Linnaeus, } \\
1758\end{array}$} & $\begin{array}{l}\text { Bélgica: Namur: } \\
\text { Warnant (B.), 7-VIII-10. } \\
\text { [Navás] }\end{array}$ & $\begin{array}{l}\text { MNCN_Ent } \\
244191\end{array}$ & & & Hembra & $\begin{array}{l}\text { Etiqueta: Panorpa germanica } q \text { L. Navás } \\
\text { S.J. det. }\end{array}$ & $\begin{array}{l}\text { I.G. Undiano, } \\
2019 \text { det. }\end{array}$ \\
\hline & & $\begin{array}{l}\text { Bélgica: Namur: } \\
\text { Warnant (B.), 7-VIII-10. } \\
\text { [Navás] }\end{array}$ & $\begin{array}{l}\text { MNCN_Ent } \\
244192\end{array}$ & & & Macho & $\begin{array}{l}\text { Etiqueta: Panorpa germanica } \hat{\jmath} \text { L. Navás } \\
\text { S.J. det. }\end{array}$ & $\begin{array}{l}\text { I.G. Undiano, } \\
2019 \text { det. }\end{array}$ \\
\hline & & $\begin{array}{l}\text { España: Cantabria: } \\
\text { Puente Viesgo, sin } \\
\text { datos. Bolivar }\end{array}$ & $\begin{array}{l}\text { MNCN_Ent } \\
24418 \overline{2}\end{array}$ & & & Hembra & nuevo dato de localidad & $\begin{array}{l}\text { I.G. Undiano, } \\
2019 \text { det. }\end{array}$ \\
\hline & & $\begin{array}{l}\text { España: Cantabria: } \\
\text { Puente Viesgo, sin } \\
\text { datos. Bolivar }\end{array}$ & $\begin{array}{l}\text { MNCN_Ent } \\
24418 \overline{3}\end{array}$ & & & Hembra & nuevo dato de localidad & $\begin{array}{l}\text { I.G. Undiano, } \\
2019 \text { det. }\end{array}$ \\
\hline & & $\begin{array}{l}\text { España: Cantabria: } \\
\text { Puente Viesgo, sin } \\
\text { datos. Bolivar }\end{array}$ & $\begin{array}{l}\text { MNCN_Ent } \\
244184\end{array}$ & & & Hembra & nuevo dato de localidad & $\begin{array}{l}\text { I.G. Undiano, } \\
2019 \text { det. }\end{array}$ \\
\hline & & $\begin{array}{l}\text { España: Cantabria: } \\
\text { Puente Viesgo, sin } \\
\text { datos. Bolivar }\end{array}$ & $\begin{array}{l}\text { MNCN_Ent } \\
24418 \overline{5}\end{array}$ & & & Hembra & nuevo dato de localidad & $\begin{array}{l}\text { I.G. Undiano, } \\
2019 \text { det. }\end{array}$ \\
\hline
\end{tabular}




\begin{tabular}{|c|c|c|c|c|c|c|c|c|}
\hline FAMILIA & ESPECIE & DATOS DE CAPTURA & $\mathrm{N}^{\circ}$ CAT. & PROCEDENCIA & ALTITUD & SEXO & OBSERVACIONES & DETERMINADO \\
\hline \multirow[t]{22}{*}{ PANORPIDAE } & \multirow{10}{*}{$\begin{array}{l}\text { Panorpa } \\
\text { germanica } \\
\text { Linnaeus, } \\
1758\end{array}$} & $\begin{array}{l}\text { España: Vizcaya: Bilbao, } \\
\text { sin datos. sin datos }\end{array}$ & $\begin{array}{l}\text { MNCN_Ent } \\
244180^{-}\end{array}$ & $\begin{array}{l}\text { Col. Seebold, } \\
\text { Mus. Madrid }\end{array}$ & & Macho & $\begin{array}{l}\text { Etiqueta: Panorpa germanica L. (Bilbao) } \\
\text { [manuscrita, aparentemente de Navás] }\end{array}$ & $\begin{array}{l}\text { I.G. Undiano, } \\
2019 \text { det. }\end{array}$ \\
\hline & & $\begin{array}{l}\text { España: Vizcaya: Bilbao, } \\
\text { sin datos. sin datos }\end{array}$ & $\begin{array}{l}\text { MNCN_Ent } \\
244181\end{array}$ & $\begin{array}{l}\text { Col. Seebold, } \\
\text { Mus. Madrid }\end{array}$ & & Hembra & & $\begin{array}{l}\text { I.G. Undiano, } \\
2019 \text { det. }\end{array}$ \\
\hline & & $\begin{array}{l}\text { Francia: Alp. Pyr., sin } \\
\text { datos. sin datos }\end{array}$ & $\begin{array}{l}\text { MNCN_Ent } \\
24418 \overline{7}\end{array}$ & $\begin{array}{l}\text { Coll. Seebold, } \\
\text { Mus. Madrid }\end{array}$ & & Hembra & & $\begin{array}{l}\text { I.G. Undiano, } \\
2019 \text { det. }\end{array}$ \\
\hline & & $\begin{array}{l}\text { Francia: Alp. Pyr., sin } \\
\text { datos. sin datos }\end{array}$ & $\begin{array}{l}\text { MNCN_Ent } \\
24418 \overline{8}^{-}\end{array}$ & $\begin{array}{l}\text { Coll. Seebold, } \\
\text { Mus. Madrid }\end{array}$ & & Macho & & $\begin{array}{l}\text { I.G. Undiano, } \\
2019 \text { det. }\end{array}$ \\
\hline & & $\begin{array}{l}\text { Francia: Hautes- } \\
\text { Pyrénées: Hautes } \\
\text { Pyrénées, Cauterets, } \\
\text { Juillet 1894. T. Seebold }\end{array}$ & $\begin{array}{l}\text { MNCN_Ent } \\
24418 \overline{6}\end{array}$ & $\begin{array}{l}\text { Coll. Seebold, } \\
\text { Mus. Madrid }\end{array}$ & & Hembra & & $\begin{array}{l}\text { I.G. Undiano, } \\
2019 \text { det. }\end{array}$ \\
\hline & & $\begin{array}{l}\text { Francia: Hautes- } \\
\text { Pyrénées: Lourdes, sin } \\
\text { datos. sin datos }\end{array}$ & $\begin{array}{l}\text { MNCN_Ent } \\
244189\end{array}$ & & & Hembra & & $\begin{array}{l}\text { I.G. Undiano, } \\
2019 \text { det. }\end{array}$ \\
\hline & & $\begin{array}{l}\text { Francia: Paris: Paris, } \\
6.5 . \text { sin datos }\end{array}$ & $\begin{array}{l}\text { MNCN_Ent } \\
244190\end{array}$ & $\begin{array}{l}\text { Coll. Seebold, } \\
\text { Mus. Madrid }\end{array}$ & & Hembra & & $\begin{array}{l}\text { I.G. Undiano, } \\
2019 \text { det. }\end{array}$ \\
\hline & & $\begin{array}{l}\text { Italia: Trieste: Castel } \\
\text { Luegghi, Trieste (Italia), } \\
\text { IX.1930. C. Bolivar }\end{array}$ & $\begin{array}{l}\text { MNCN_Ent } \\
244193\end{array}$ & & & Hembra & & $\begin{array}{l}\text { I.G. Undiano, } \\
2019 \text { det. }\end{array}$ \\
\hline & & $\begin{array}{l}\text { Rumania: Cluj: } \\
\text { Lacul Tarnita, 21-VII- } \\
\text { 2011. M. GaParís, J. } \\
\text { Vörös }\end{array}$ & $\begin{array}{l}\text { MNCN_Ent } \\
25496 \overline{8}\end{array}$ & & $600 \mathrm{~m}$ & Hembra & Alcohol & $\begin{array}{l}\text { I.G. Undiano, } \\
2019 \text { det. }\end{array}$ \\
\hline & & $\begin{array}{l}\text { Rumania: Cluj: } \\
\text { Lacul Tarnita, 21-VVI- } \\
\text { 2011. M. GaParís, J. } \\
\text { Vörös }\end{array}$ & $\begin{array}{l}\text { MNCN_Ent } \\
254970^{-}\end{array}$ & & $600 \mathrm{~m}$ & Hembra & Alcohol & $\begin{array}{l}\text { I.G. Undiano, } \\
2019 \text { det. }\end{array}$ \\
\hline & \multirow[t]{12}{*}{$\begin{array}{l}\text { Panorpa } \\
\text { meridionalis } \\
\text { Rambur, } 1842\end{array}$} & $\begin{array}{l}\text { Bélgica: Valonia: Haut } \\
\text { le Wastia, 14.VIl.7. sin } \\
\text { datos }\end{array}$ & $\begin{array}{l}\text { MNCN_Ent } \\
244172\end{array}$ & & & Hembra & $\begin{array}{l}\text { Etiqueta: Panorpa communis L. Navás } \\
\text { S.J. det. }\end{array}$ & $\begin{array}{l}\text { I.G. Undiano, } \\
2019 \text { det. }\end{array}$ \\
\hline & & $\begin{array}{l}\text { España: A Coruña: } \\
\text { Coruña, sin datos. } \\
\text { Bolivar }\end{array}$ & $\begin{array}{l}\text { MNCN_Ent } \\
244110^{-}\end{array}$ & & & Hembra & nuevo dato de localidad & $\begin{array}{l}\text { I.G. Undiano, } \\
2019 \text { det. }\end{array}$ \\
\hline & & $\begin{array}{l}\text { España: A Coruña: } \\
\text { Coruña, sin datos. } \\
\text { Bolivar }\end{array}$ & $\begin{array}{l}\text { MNCN_Ent } \\
244111\end{array}$ & & & Hembra & nuevo dato de localidad & $\begin{array}{l}\text { I.G. Undiano, } \\
2019 \text { det. }\end{array}$ \\
\hline & & $\begin{array}{l}\text { España: A Coruña: Villa } \\
\text { Rutis (La Coruña), sin } \\
\text { datos. Bolivar }\end{array}$ & $\begin{array}{l}\text { MNCN_Ent } \\
244109\end{array}$ & & & Hembra & $\begin{array}{l}\text { Etiqueta: P. meridionalis Rb. v. fenestrata } \\
\text { Nav. [manuscrita, aparentemente de } \\
\text { Navás], nuevo dato de localidad }\end{array}$ & $\begin{array}{l}\text { I.G. Undiano, } \\
2019 \text { det. }\end{array}$ \\
\hline & & $\begin{array}{l}\text { España: Asturias: El } \\
\text { Puerto: Parque de } \\
\text { Somiedo, 24-VII-2010. } \\
\text { J.G. Rodriguez }\end{array}$ & $\begin{array}{l}\text { MNCN_Ent } \\
25499 \overline{8}\end{array}$ & & & Hembra & Alcohol, nuevo dato de localidad & $\begin{array}{l}\text { I.G. Undiano, } \\
2019 \text { det. }\end{array}$ \\
\hline & & $\begin{array}{l}\text { España: Ávila: Valle de } \\
\text { Iruelas, Prov. de Ávila, } \\
\text { VI-1920. Bolivar }\end{array}$ & $\begin{array}{l}\text { MNCN_Ent } \\
244107\end{array}$ & & & Hembra & nuevo dato de localidad & $\begin{array}{l}\text { I.G. Undiano, } \\
2019 \text { det. }\end{array}$ \\
\hline & & $\begin{array}{l}\text { España: Badajoz: Oliva } \\
\text { de la Frontera, 22-V- } \\
\text { 2001. M. Ga. Paris }\end{array}$ & $\begin{array}{l}\text { MNCN_Ent } \\
244108\end{array}$ & & & Macho & nuevo dato de localidad & $\begin{array}{l}\text { I.G. Undiano, } \\
2019 \text { det. }\end{array}$ \\
\hline & & $\begin{array}{l}\text { España: Barcelona: } \\
\text { Barcelona, sin datos. } \\
\text { sin datos }\end{array}$ & $\begin{array}{l}\text { MNCN_Ent } \\
24415 \overline{5}\end{array}$ & & & Hembra & & $\begin{array}{l}\text { I.G. Undiano, } \\
2019 \text { det. }\end{array}$ \\
\hline & & $\begin{array}{l}\text { España: Barcelona: } \\
\text { Barcelona, sin datos. } \\
\text { Antiga }\end{array}$ & $\begin{array}{l}\text { MNCN_Ent } \\
244156\end{array}$ & $\begin{array}{l}\text { Col. Maz. Boliv. } \\
\text { [Colección } \\
\text { Mazarredo } \\
\text { Bolívar] }\end{array}$ & & Hembra & $\begin{array}{l}\text { Etiqueta: Panorpa meridionalis Rb. } \\
\text { [manuscrita, aparentemente de Navás] }\end{array}$ & $\begin{array}{l}\text { I.G. Undiano, } \\
2019 \text { det. }\end{array}$ \\
\hline & & $\begin{array}{l}\text { España: Barcelona: } \\
\text { Montserrat, VIII-32. Gil }\end{array}$ & $\begin{array}{l}\text { MNCN_Ent } \\
24415 \overline{4}\end{array}$ & & & Hembra & & $\begin{array}{l}\text { I.G. Undiano, } \\
2019 \text { det. }\end{array}$ \\
\hline & & $\begin{array}{l}\text { España: Burgos: } \\
\text { Ameyugo: Sierra de } \\
\text { Obarenes, sin datos. M. } \\
\text { GaParís }\end{array}$ & $\begin{array}{l}\text { MNCN_Ent } \\
254996\end{array}$ & & & Macho & Alcohol, nuevo dato de localidad & $\begin{array}{l}\text { I.G. Undiano, } \\
2019 \text { det. }\end{array}$ \\
\hline & & $\begin{array}{l}\text { España: Burgos: } \\
\text { Ameyugo: Sierra de } \\
\text { Obarenes, sin datos. M. } \\
\text { GaParís }\end{array}$ & $\begin{array}{l}\text { MNCN_Ent } \\
254997\end{array}$ & & & Macho & Alcohol, nuevo dato de localidad & $\begin{array}{l}\text { I.G. Undiano, } \\
2019 \text { det. }\end{array}$ \\
\hline
\end{tabular}




\begin{tabular}{|c|c|c|c|c|c|c|c|c|}
\hline FAMILIA & ESPECIE & DATOS DE CAPTURA & $\mathrm{N}^{\circ}$ CAT. & PROCEDENCIA & ALTITUD & SEXO & OBSERVACIONES & DETERMINADO \\
\hline \multirow[t]{20}{*}{ PANORPIDAE } & $\begin{array}{l}\text { Panorpa } \\
\text { meridionalis } \\
\text { Rambur, } 1842\end{array}$ & $\begin{array}{l}\text { España: Cáceres: } \\
\text { Acebo, 17-IV-2011. M. } \\
\text { GaParís }\end{array}$ & $\begin{array}{l}\text { MNCN_Ent } \\
255010\end{array}$ & & $525 \mathrm{~m}$. & Hembra & Alcohol, nuevo dato de localidad & $\begin{array}{l}\text { I.G. Undiano, } \\
2019 \text { det. }\end{array}$ \\
\hline & & $\begin{array}{l}\text { España: Cáceres: } \\
\text { Navatrasierra, 12-V- } \\
\text { 2012. M. GParís }\end{array}$ & $\begin{array}{l}\text { MNCN_Ent } \\
25497 \overline{2}\end{array}$ & & $1.004 \mathrm{~m}$. & Macho & Alcohol, nuevo dato de localidad & $\begin{array}{l}\text { I.G. Undiano, } \\
2019 \text { det. }\end{array}$ \\
\hline & & $\begin{array}{l}\text { España: Cáceres: } \\
\text { Navatrasierra, 12-V- } \\
\text { 2012. M. G'París }\end{array}$ & $\begin{array}{l}\text { MNCN_Ent } \\
25497 \overline{3}\end{array}$ & & $1.004 \mathrm{~m}$. & Macho & Alcohol, nuevo dato de localidad & $\begin{array}{l}\text { I.G. Undiano, } \\
2019 \text { det. }\end{array}$ \\
\hline & & $\begin{array}{l}\text { España: Cáceres: } \\
\text { Navatrasierra, 12-V- } \\
\text { 2012. M. GParís }\end{array}$ & $\begin{array}{l}\text { MNCN_Ent } \\
25497 \overline{4}\end{array}$ & & $1.004 \mathrm{~m}$. & Hembra & Alcohol, nuevo dato de localidad & $\begin{array}{l}\text { I.G. Undiano, } \\
2019 \text { det. }\end{array}$ \\
\hline & & $\begin{array}{l}\text { España: Cáceres: } \\
\text { Navatrasierra, 12-V- } \\
\text { 2012. M. GaParís }\end{array}$ & $\begin{array}{l}\text { MNCN_Ent } \\
25497 \overline{5}\end{array}$ & & $1.004 \mathrm{~m}$ & Hembra & Alcohol, nuevo dato de localidad & $\begin{array}{l}\text { I.G. Undiano, } \\
2019 \text { det. }\end{array}$ \\
\hline & & $\begin{array}{l}\text { España: Cáceres: Santa } \\
\text { Cruz de la Sierra, 29-IV- } \\
\text { 2007. M. GaParís }\end{array}$ & $\begin{array}{l}\text { MNCN_Ent } \\
25499 \overline{2}\end{array}$ & & & Hembra & Alcohol, nuevo dato de localidad & $\begin{array}{l}\text { I.G. Undiano, } \\
2019 \text { det. }\end{array}$ \\
\hline & & $\begin{array}{l}\text { España: Cáceres: Santa } \\
\text { Cruz de la Sierra, 29-IV- } \\
\text { 2007. M. GaParis }\end{array}$ & $\begin{array}{l}\text { MNCN_Ent } \\
25499 \overline{3}\end{array}$ & & & Hembra & Alcohol, nuevo dato de localidad & $\begin{array}{l}\text { I.G. Undiano, } \\
2019 \text { det. }\end{array}$ \\
\hline & & $\begin{array}{l}\text { España: Cantabria: San } \\
\text { Roque de Riomiera } \\
\text { (Cantabria), 20-VI/4- } \\
\text { VII/2010. C. Rey }\end{array}$ & $\begin{array}{l}\text { MNCN_Ent } \\
251031\end{array}$ & & $570 \mathrm{~m}$. & Macho & $\begin{array}{l}\text { Trampa Malaise. Alcohol, nuevo dato de } \\
\text { localidad }\end{array}$ & $\begin{array}{l}\text { I.G. Undiano, } \\
2019 \text { det. }\end{array}$ \\
\hline & & $\begin{array}{l}\text { España: Cantabria: San } \\
\text { Roque de Riomiera } \\
\text { (Cantabria), 20-VI/4- } \\
\text { VII/2010. C. Rey }\end{array}$ & $\begin{array}{l}\text { MNCN_Ent } \\
25103 \overline{2}\end{array}$ & & $570 \mathrm{~m}$. & Hembra & $\begin{array}{l}\text { Trampa Malaise. Alcohol, nuevo dato de } \\
\text { localidad }\end{array}$ & $\begin{array}{l}\text { I.G. Undiano, } \\
2019 \text { det. }\end{array}$ \\
\hline & & $\begin{array}{l}\text { España: Ciudad Real: } \\
\text { Pozuelo de Calatrava, } \\
\text { sin datos. sin datos }\end{array}$ & $\begin{array}{l}\text { MNCN_Ent } \\
244091\end{array}$ & & & Macho & nuevo dato de localidad & $\begin{array}{l}\text { I.G. Undiano, } \\
2019 \text { det. }\end{array}$ \\
\hline & & $\begin{array}{l}\text { España: Ciudad Real: } \\
\text { Pozuelo de Calatr., sin } \\
\text { datos. sin datos }\end{array}$ & $\begin{array}{l}\text { MNCN_Ent } \\
24409 \overline{2}\end{array}$ & & & Macho & nuevo dato de localidad & $\begin{array}{l}\text { I.G. Undiano, } \\
2019 \text { det. }\end{array}$ \\
\hline & & $\begin{array}{l}\text { España: Ciudad Real: } \\
\text { Pozuelo de Calatrava, } \\
\text { sin datos. sin datos }\end{array}$ & $\begin{array}{l}\text { MNCN_Ent } \\
24409 \overline{3}\end{array}$ & & & Macho & nuevo dato de localidad & $\begin{array}{l}\text { I.G. Undiano, } \\
2019 \text { det. }\end{array}$ \\
\hline & & $\begin{array}{l}\text { España: Córdoba: El } \\
\text { Cabril, Hornachuelos } \\
\text { (Córdoba), (7-28)-IV- } \\
\text { 2014. Nieves \& Rey }\end{array}$ & $\begin{array}{l}\text { MNCN_Ent } \\
170426\end{array}$ & & $300 \mathrm{~m}$. & Hembra & $\begin{array}{l}\text { Trampa Malaise. Alcohol, nuevo dato de } \\
\text { localidad }\end{array}$ & $\begin{array}{l}\text { I.G. Undiano, } \\
2019 \text { det. }\end{array}$ \\
\hline & & $\begin{array}{l}\text { España: Córdoba: El } \\
\text { Cabril, Hornachuelos } \\
\text { (Córdoba), (7-28)-IV- } \\
\text { 2014. Nieves \& Rey }\end{array}$ & $\begin{array}{l}\text { MNCN_Ent } \\
17042 \overline{7}\end{array}$ & & $300 \mathrm{~m}$. & Hembra & $\begin{array}{l}\text { Trampa Malaise. Alcohol, nuevo dato de } \\
\text { localidad }\end{array}$ & $\begin{array}{l}\text { I.G. Undiano, } \\
2019 \text { det. }\end{array}$ \\
\hline & & $\begin{array}{l}\text { España: Córdoba: El } \\
\text { Cabril, Hornachuelos } \\
\text { (Córdoba), (7-28)-IV- } \\
\text { 2014. Nieves \& Rey }\end{array}$ & $\begin{array}{l}\text { MNCN_Ent } \\
170428\end{array}$ & & $300 \mathrm{~m}$. & Hembra & $\begin{array}{l}\text { Trampa Malaise. Alcohol, nuevo dato de } \\
\text { localidad }\end{array}$ & $\begin{array}{l}\text { I.G. Undiano, } \\
2019 \text { det. }\end{array}$ \\
\hline & & $\begin{array}{l}\text { España: Cuenca: } \\
\text { Cañizares, sin datos. } \\
\text { Selgas }\end{array}$ & $\begin{array}{l}\text { MNCN_Ent } \\
24408 \overline{7}\end{array}$ & & & Hembra & nuevo dato de localidad & $\begin{array}{l}\text { I.G. Undiano, } \\
2019 \text { det. }\end{array}$ \\
\hline & & $\begin{array}{l}\text { España: Cuenca: } \\
\text { Ciudad Encantada } \\
\text { (Cuenca), sin datos. } \\
\text { Bolivar }\end{array}$ & $\begin{array}{l}\text { MNCN_Ent } \\
24408 \overline{8}\end{array}$ & & & Hembra & nuevo dato de localidad & $\begin{array}{l}\text { I.G. Undiano, } \\
2019 \text { det. }\end{array}$ \\
\hline & & $\begin{array}{l}\text { España: Cuenca: } \\
\text { Cuenca, Julio } 1906 . \\
\text { Arias }\end{array}$ & $\begin{array}{l}\text { MNCN_Ent } \\
24408 \overline{9}\end{array}$ & & & Macho & & $\begin{array}{l}\text { I.G. Undiano, } \\
2019 \text { det. }\end{array}$ \\
\hline & & $\begin{array}{l}\text { España: Cuenca: } \\
\text { Tragacete, Julio } 1906 . \\
\text { Arias }\end{array}$ & $\begin{array}{l}\text { MNCN_Ent } \\
244090\end{array}$ & & & Hembra & nuevo dato de localidad & $\begin{array}{l}\text { I.G. Undiano, } \\
2019 \text { det. }\end{array}$ \\
\hline & & $\begin{array}{l}\text { España: Girona: Coll } \\
\text { de Toses, 3-VII-2011. } \\
\text { M. GaParís, V. DeJesús, } \\
\text { P. Pavón }\end{array}$ & $\begin{array}{l}\text { MNCN_Ent } \\
25495 \overline{6}\end{array}$ & & & Hembra & Alcohol & $\begin{array}{l}\text { I.G. Undiano, } \\
2019 \text { det. }\end{array}$ \\
\hline
\end{tabular}




\begin{tabular}{|c|c|c|c|c|c|c|c|c|}
\hline FAMILIA & ESPECIE & DATOS DE CAPTURA & $\mathrm{N}^{\circ}$ CAT. & PROCEDENCIA & ALTITUD & SEXO & OBSERVACIONES & DETERMINADO \\
\hline \multirow[t]{23}{*}{ PANORPIDAE } & $\begin{array}{l}\text { Panorpa } \\
\text { meridionalis } \\
\text { Rambur, } 1842\end{array}$ & $\begin{array}{l}\text { España: Girona: Santa } \\
\text { Coloma de Farnés, 26- } \\
\text { VI-2009. J.G. Rodríguez }\end{array}$ & $\begin{array}{l}\text { MNCN_Ent } \\
255000^{-}\end{array}$ & & & Macho & Alcohol & $\begin{array}{l}\text { I.G. Undiano, } \\
2019 \text { det. }\end{array}$ \\
\hline & & $\begin{array}{l}\text { España: Girona: Santa } \\
\text { Coloma de Farnés, 26- } \\
\text { VI-2009. J.G. Rodríguez }\end{array}$ & $\begin{array}{l}\text { MNCN_Ent } \\
255001\end{array}$ & & & Hembra & Alcohol & $\begin{array}{l}\text { I.G. Undiano, } \\
2019 \text { det. }\end{array}$ \\
\hline & & $\begin{array}{l}\text { España: Granada: } \\
\text { La Sagra, sin datos. } \\
\text { Escalera }\end{array}$ & $\begin{array}{l}\text { MNCN_Ent } \\
24415 \overline{8}\end{array}$ & & & Hembra & nuevo dato de localidad & $\begin{array}{l}\text { I.G. Undiano, } \\
2019 \text { det. }\end{array}$ \\
\hline & & $\begin{array}{l}\text { España: Granada: } \\
\text { La Sagra, sin datos. } \\
\text { Escalera }\end{array}$ & $\begin{array}{l}\text { MNCN_Ent } \\
24415 \overline{9}\end{array}$ & & & Hembra & nuevo dato de localidad & $\begin{array}{l}\text { I.G. Undiano, } \\
2019 \text { det. }\end{array}$ \\
\hline & & $\begin{array}{l}\text { España: Granada: Río } \\
\text { Fardes (Granada), } \\
\text { V-1966. Dr. Fidel Fdez. } \\
\text { Rubio }\end{array}$ & $\begin{array}{l}\text { MNCN Ent } \\
24415 \overline{7}\end{array}$ & & $1.400 \mathrm{~m}$. & Macho & nuevo dato de localidad & $\begin{array}{l}\text { I.G. Undiano, } \\
2019 \text { det. }\end{array}$ \\
\hline & & $\begin{array}{l}\text { España: Huelva: } \\
\text { Calañas, 30-IV-2007. } \\
\text { M. GaParis }\end{array}$ & $\begin{array}{l}\text { MNCN_Ent } \\
25499 \overline{5}\end{array}$ & & & Macho & Alcohol, nuevo dato de localidad & $\begin{array}{l}\text { I.G. Undiano, } \\
2019 \text { det. }\end{array}$ \\
\hline & & $\begin{array}{l}\text { España: Huesca: } \\
\text { Bujaruelo, Prov. de } \\
\text { Huesca, 10-VII- } \\
\text { 1943. Exp. Inst. de } \\
\text { Entomologia }\end{array}$ & $\begin{array}{l}\text { MNCN_Ent } \\
244121\end{array}$ & & $1.338 \mathrm{~m}$. & Hembra & $\begin{array}{l}\text { Etiqueta: Panorpa communis L. / Det. } \\
\text { A. Benitez }\end{array}$ & $\begin{array}{l}\text { I.G. Undiano, } \\
2019 \text { det. }\end{array}$ \\
\hline & & $\begin{array}{l}\text { España: Huesca: } \\
\text { Candanchú, Canfranc } \\
\text { (Huesca), sin datos. J. } \\
\text { M. Dusmet }\end{array}$ & $\begin{array}{l}\text { MNCN_Ent } \\
244122\end{array}$ & & $1.400 \mathrm{~m}$. & Macho & & $\begin{array}{l}\text { I.G. Undiano, } \\
2019 \text { det. }\end{array}$ \\
\hline & & $\begin{array}{l}\text { España: Huesca: } \\
\text { Castarné, 28-VIII-2008. } \\
\text { M. GaParis, N.P. Daniel, } \\
\text { G.G. Martín }\end{array}$ & $\begin{array}{l}\text { MNCN_Ent } \\
25500 \overline{7}\end{array}$ & & $919 \mathrm{~m}$. & Hembra & Alcohol & $\begin{array}{l}\text { I.G. Undiano, } \\
2019 \text { det. }\end{array}$ \\
\hline & & $\begin{array}{l}\text { España: Huesca: } \\
\text { Cerler, 28-VIII-2008. } \\
\text { M. GaParís, N.P. Daniel, } \\
\text { G.G. Martín }\end{array}$ & $\begin{array}{l}\text { MNCN_Ent } \\
25500 \overline{8}\end{array}$ & & $1.512 \mathrm{~m}$. & Hembra & Alcohol & $\begin{array}{l}\text { I.G. Undiano, } \\
2019 \text { det. }\end{array}$ \\
\hline & & $\begin{array}{l}\text { España: Huesca: Jaca, } \\
\text { sin datos. sin datos }\end{array}$ & $\begin{array}{l}\text { MNCN_Ent } \\
24412 \overline{9}\end{array}$ & & & Hembra & & $\begin{array}{l}\text { I.G. Undiano, } \\
2019 \text { det. }\end{array}$ \\
\hline & & $\begin{array}{l}\text { España: Huesca: } \\
\text { Panticosa, Prov. de } \\
\text { Huesca, 10-18-43. M. } \\
\text { Bohigas }\end{array}$ & $\begin{array}{l}\text { MNCN_Ent } \\
24413 \overline{5}\end{array}$ & & $1.800 \mathrm{~m}$. & Macho & & $\begin{array}{l}\text { I.G. Undiano, } \\
2019 \text { det. }\end{array}$ \\
\hline & & $\begin{array}{l}\text { España: Huesca: } \\
\text { Panticosa, sin datos. } \\
\text { sin datos }\end{array}$ & $\begin{array}{l}\text { MNCN_Ent } \\
244130^{-}\end{array}$ & & & Hembra & & $\begin{array}{l}\text { I.G. Undiano, } \\
2019 \text { det. }\end{array}$ \\
\hline & & $\begin{array}{l}\text { España: Huesca: } \\
\text { Panticosa, sin datos. } \\
\text { Escalera }\end{array}$ & $\begin{array}{l}\text { MNCN_Ent } \\
244131^{-}\end{array}$ & & & Hembra & $\begin{array}{l}\text { Etiqueta: Panorpa meridionalis Rb. } \\
\text { (Panticosa) [manuscrita, aparentemente } \\
\text { de Navás] }\end{array}$ & $\begin{array}{l}\text { I.G. Undiano, } \\
2019 \text { det. }\end{array}$ \\
\hline & & $\begin{array}{l}\text { España: Huesca: } \\
\text { Panticosa, sin datos. } \\
\text { Escalera }\end{array}$ & $\begin{array}{l}\text { MNCN_Ent } \\
244132\end{array}$ & & & Hembra & $\begin{array}{l}\text { Etiqueta: Panorpa meridionalis Ramb. } \\
\text { [manuscrita, aparentemente de Navás] }\end{array}$ & $\begin{array}{l}\text { I.G. Undiano, } \\
2019 \text { det. }\end{array}$ \\
\hline & & $\begin{array}{l}\text { España: Huesca: } \\
\text { Panticosa, sin datos. } \\
\text { Escalera }\end{array}$ & $\begin{array}{l}\text { MNCN Ent } \\
24413 \overline{3}\end{array}$ & & & Hembra & & $\begin{array}{l}\text { I.G. Undiano, } \\
2019 \text { det. }\end{array}$ \\
\hline & & $\begin{array}{l}\text { España: Huesca: } \\
\text { Panticosa, sin datos. } \\
\text { Escalera }\end{array}$ & $\begin{array}{l}\text { MNCN_Ent } \\
24413 \overline{4}\end{array}$ & & & Hembra & & $\begin{array}{l}\text { I.G. Undiano, } \\
2019 \text { det. }\end{array}$ \\
\hline & & $\begin{array}{l}\text { España: Huesca: Pineta, } \\
\text { VIII-1967. E. Ortiz }\end{array}$ & $\begin{array}{l}\text { MNCN_Ent } \\
24412 \overline{5}\end{array}$ & & & Hembra & & $\begin{array}{l}\text { I.G. Undiano, } \\
2019 \text { det. }\end{array}$ \\
\hline & & $\begin{array}{l}\text { España: Huesca: Pineta, } \\
\text { VIII-1967. E. Ortiz }\end{array}$ & $\begin{array}{l}\text { MNCN_Ent } \\
24412 \overline{6}\end{array}$ & & & Macho & & $\begin{array}{l}\text { I.G. Undiano, } \\
2019 \text { det. }\end{array}$ \\
\hline & & $\begin{array}{l}\text { España: Huesca: Pueyo } \\
\text { de Jaca (Huesca), VIl- } \\
56 . \sin \text { datos }\end{array}$ & $\begin{array}{l}\text { MNCN Ent } \\
24412 \overline{8}\end{array}$ & & $1.200 \mathrm{~m}$. & Hembra & & $\begin{array}{l}\text { I.G. Undiano, } \\
2019 \text { det. }\end{array}$ \\
\hline & & $\begin{array}{l}\text { España: Huesca: Pueyo } \\
\text { de Jaca, 11-VII-1976. } \\
\text { C. Rey }\end{array}$ & $\begin{array}{l}\text { MNCN Ent } \\
24412 \overline{7}\end{array}$ & & & Hembra & & $\begin{array}{l}\text { I.G. Undiano, } \\
2019 \text { det. }\end{array}$ \\
\hline & & $\begin{array}{l}\text { España: Huesca: S. } \\
\text { Guara, 15-VII-905. } \\
\text { Bolívar }\end{array}$ & $\begin{array}{l}\text { MNCN Ent } \\
24413 \overline{9}\end{array}$ & & & Macho & & $\begin{array}{l}\text { I.G. Undiano, } \\
2019 \text { det. }\end{array}$ \\
\hline & & $\begin{array}{l}\text { España: Huesca: S. } \\
\text { Guara, } 16-V \mathrm{VI}-905 . \\
\text { Bolívar }\end{array}$ & $\begin{array}{l}\text { MNCN_Ent } \\
244140^{-}\end{array}$ & & & Macho & & $\begin{array}{l}\text { I.G. Undiano, } \\
2019 \text { det. }\end{array}$ \\
\hline
\end{tabular}




\begin{tabular}{|c|c|c|c|c|c|c|c|c|}
\hline FAMILIA & ESPECIE & DATOS DE CAPTURA & $\mathrm{N}^{\circ}$ CAT. & PROCEDENCIA & ALTITUD & SEXO & OBSERVACIONES & DETERMINADO \\
\hline \multirow[t]{19}{*}{ PANORPIDAE } & $\begin{array}{l}\text { Panorpa } \\
\text { meridionalis } \\
\text { Rambur, } 1842\end{array}$ & $\begin{array}{l}\text { España: Huesca: Selva } \\
\text { de Zuriza, Ansó, Prov. } \\
\text { de Huesca, 1-VII-43. M. } \\
\text { Bohigas }\end{array}$ & $\begin{array}{l}\text { MNCN_Ent } \\
244123\end{array}$ & & $2.100 \mathrm{~m}$ & Macho & & $\begin{array}{l}\text { I.G. Undiano, } \\
2019 \text { det. }\end{array}$ \\
\hline & & $\begin{array}{l}\text { España: Huesca: Valle } \\
\text { Canfranc, sin datos. sin } \\
\text { datos. }\end{array}$ & $\begin{array}{l}\text { MNCN_Ent } \\
244124\end{array}$ & & $\begin{array}{l}1.200- \\
1.400 \mathrm{~m} .\end{array}$ & Hembra & & $\begin{array}{l}\text { I.G. Undiano, } \\
2019 \text { det. }\end{array}$ \\
\hline & & $\begin{array}{l}\text { España: Huesca: Valle } \\
\text { de Ordesa (Huesca), } \\
\text { VII-1934. C. Bolivar }\end{array}$ & $\begin{array}{l}\text { MNCN_Ent } \\
244114\end{array}$ & & & Hembra & & $\begin{array}{l}\text { I.G. Undiano, } \\
2019 \text { det. }\end{array}$ \\
\hline & & $\begin{array}{l}\text { España: Huesca: Valle } \\
\text { de Ordesa (Huesca), } \\
\text { VII-1934. C. Bolívar }\end{array}$ & $\begin{array}{l}\text { MNCN_Ent } \\
24411 \overline{5}\end{array}$ & & & Hembra & & $\begin{array}{l}\text { I.G. Undiano, } \\
2019 \text { det. }\end{array}$ \\
\hline & & $\begin{array}{l}\text { España: Huesca: Valle } \\
\text { de Ordesa (Huesca), } \\
\text { VII-1934. C. Bolívar }\end{array}$ & $\begin{array}{l}\text { MNCN_Ent } \\
24411 \overline{6}\end{array}$ & & & Hembra & & $\begin{array}{l}\text { I.G. Undiano, } \\
2019 \text { det. }\end{array}$ \\
\hline & & $\begin{array}{l}\text { España: Huesca: Valle } \\
\text { de Ordesa (Huesca), } \\
\text { VII-1934. C. Bolívar }\end{array}$ & $\begin{array}{l}\text { MNCN_Ent } \\
244117\end{array}$ & & & Hembra & & $\begin{array}{l}\text { I.G. Undiano, } \\
2019 \text { det. }\end{array}$ \\
\hline & & $\begin{array}{l}\text { España: Huesca: Valle } \\
\text { de Ordesa (Huesca), } \\
\text { VII-1934. C. Bolívar }\end{array}$ & $\begin{array}{l}\text { MNCN_Ent } \\
244118\end{array}$ & & & Hembra & & $\begin{array}{l}\text { I.G. Undiano, } \\
2019 \text { det. }\end{array}$ \\
\hline & & $\begin{array}{l}\text { España: Huesca: Valle } \\
\text { de Ordesa (Huesca), } \\
\text { VII-1934. C. Bolívar }\end{array}$ & $\begin{array}{l}\text { MNCN_Ent } \\
244119\end{array}$ & & & Macho & & $\begin{array}{l}\text { I.G. Undiano, } \\
2019 \text { det. }\end{array}$ \\
\hline & & $\begin{array}{l}\text { España: Huesca: Valle } \\
\text { de Ordesa (Huesca), } \\
\text { VIl-1934. C. Bolívar }\end{array}$ & $\begin{array}{l}\text { MNCN_Ent } \\
244120\end{array}$ & & & Hembra & & $\begin{array}{l}\text { I.G. Undiano, } \\
2019 \text { det. }\end{array}$ \\
\hline & & $\begin{array}{l}\text { España: León: El } \\
\text { Barroso de Rioscuro, } \\
\text { Villablino (León), 26-30- } \\
\text { VIl-1949. Exp. Inst. Esp. } \\
\text { Entomología }\end{array}$ & $\begin{array}{l}\text { MNCN_Ent } \\
244094\end{array}$ & & & Macho & nuevo dato de localidad & $\begin{array}{l}\text { I.G. Undiano, } \\
2019 \text { det. }\end{array}$ \\
\hline & & $\begin{array}{l}\text { España: León: El } \\
\text { Barroso de Rioscuro, } \\
\text { Villablino (León), 26-30- } \\
\text { VIl-1949. Exp. Inst. Esp. } \\
\text { Entomología }\end{array}$ & $\begin{array}{l}\text { MNCN_Ent } \\
244095\end{array}$ & & & Hembra & nuevo dato de localidad & $\begin{array}{l}\text { I.G. Undiano, } \\
2019 \text { det. }\end{array}$ \\
\hline & & $\begin{array}{l}\text { España: León: Villablino } \\
\text { (León), 20-30-VII- } \\
\text { 1950. Exp. Inst. Esp. } \\
\text { Entomología }\end{array}$ & $\begin{array}{l}\text { MNCN_Ent } \\
244096\end{array}$ & & $1.000 \mathrm{~m}$ & Hembra & nuevo dato de localidad & $\begin{array}{l}\text { I.G. Undiano, } \\
2019 \text { det. }\end{array}$ \\
\hline & & $\begin{array}{l}\text { España: León: Villablino } \\
\text { (León), 20-30-VII- } \\
\text { 1950. Exp. Inst. Esp. } \\
\text { Entomología }\end{array}$ & $\begin{array}{l}\text { MNCN_Ent } \\
244097\end{array}$ & & $1.000 \mathrm{~m}$ & Macho & nuevo dato de localidad & $\begin{array}{l}\text { I.G. Undiano, } \\
2019 \text { det. }\end{array}$ \\
\hline & & $\begin{array}{l}\text { España: León: Villablino, } \\
\text { Prov. de León, 10-13- } \\
\text { VIII-941. E. Zarco }\end{array}$ & $\begin{array}{l}\text { MNCN_Ent } \\
244098\end{array}$ & & $1.000 \mathrm{~m}$ & Macho & nuevo dato de localidad & $\begin{array}{l}\text { I.G. Undiano, } \\
2019 \text { det. }\end{array}$ \\
\hline & & $\begin{array}{l}\text { España: León: Villablino, } \\
\text { Prov. de León, 10-13- } \\
\text { VIII-941. E. Zarco }\end{array}$ & $\begin{array}{l}\text { MNCN_Ent } \\
244099\end{array}$ & & $1.000 \mathrm{~m}$ & Hembra & nuevo dato de localidad & $\begin{array}{l}\text { I.G. Undiano, } \\
2019 \text { det. }\end{array}$ \\
\hline & & $\begin{array}{l}\text { España: León: Villablino, } \\
\text { Prov. de León, 10-13- } \\
\text { VIII-941. J. Abajo }\end{array}$ & $\begin{array}{l}\text { MNCN_Ent } \\
244100\end{array}$ & & $1.000 \mathrm{~m}$ & Hembra & nuevo dato de localidad & $\begin{array}{l}\text { I.G. Undiano, } \\
2019 \text { det. }\end{array}$ \\
\hline & & $\begin{array}{l}\text { España: León: Villablino, } \\
\text { Prov. de León, 10-13- } \\
\text { VIII-941. J. Abajo }\end{array}$ & $\begin{array}{l}\text { MNCN_Ent } \\
244101\end{array}$ & & $1.000 \mathrm{~m}$ & Hembra & nuevo dato de localidad & $\begin{array}{l}\text { I.G. Undiano, } \\
2019 \text { det. }\end{array}$ \\
\hline & & $\begin{array}{l}\text { España: León: Villablino, } \\
\text { Prov. de León, 10-13- } \\
\text { VIII-941. J. Abajo }\end{array}$ & $\begin{array}{l}\text { MNCN_Ent } \\
244102\end{array}$ & & $1.000 \mathrm{~m}$ & Macho & nuevo dato de localidad & $\begin{array}{l}\text { I.G. Undiano, } \\
2019 \text { det. }\end{array}$ \\
\hline & & $\begin{array}{l}\text { España: León: Villablino, } \\
\text { Prov. de León, 10-13- } \\
\text { VIII-941. J. Abajo }\end{array}$ & $\begin{array}{l}\text { MNCN_Ent } \\
244103\end{array}$ & & $1.000 \mathrm{~m}$ & Macho & nuevo dato de localidad & $\begin{array}{l}\text { I.G. Undiano, } \\
2019 \text { det. }\end{array}$ \\
\hline
\end{tabular}




\begin{tabular}{|c|c|c|c|c|c|c|c|c|}
\hline FAMILIA & ESPECIE & DATOS DE CAPTURA & $N^{\circ}$ CAT. & PROCEDENCIA & ALTITUD & SEXO & OBSERVACIONES & DETERMINADO \\
\hline \multirow[t]{20}{*}{ PANORPIDAE } & $\begin{array}{l}\text { Panorpa } \\
\text { meridionalis } \\
\text { Rambur, } 1842\end{array}$ & $\begin{array}{l}\text { España: León: Villablino, } \\
\text { Prov. de León, 10-13- } \\
\text { VIII-941. J. Abajo }\end{array}$ & $\begin{array}{l}\text { MNCN_Ent } \\
24410 \overline{4}\end{array}$ & & $1.000 \mathrm{~m}$. & Macho & nuevo dato de localidad & $\begin{array}{l}\text { I.G. Undiano, } \\
2019 \text { det. }\end{array}$ \\
\hline & & $\begin{array}{l}\text { España: León: Villablino, } \\
\text { Prov. de León, 10-13- } \\
\text { VIII-941. J. Abajo }\end{array}$ & $\begin{array}{l}\text { MNCN Ent } \\
24410 \overline{5}\end{array}$ & & $1.000 \mathrm{~m}$. & Macho & nuevo dato de localidad & $\begin{array}{l}\text { I.G. Undiano, } \\
2019 \text { det. }\end{array}$ \\
\hline & & $\begin{array}{l}\text { España: León: Villablino, } \\
\text { Prov. de León, 10-13- } \\
\text { VIII-941. J. Abajo }\end{array}$ & $\begin{array}{l}\text { MNCN_Ent } \\
25485 \overline{5}\end{array}$ & & $1.000 \mathrm{~m}$. & Macho & $\begin{array}{l}\text { Etiqueta con número } 41 \text {, nuevo dato de } \\
\text { localidad }\end{array}$ & $\begin{array}{l}\text { I.G. Undiano, } \\
2019 \text { det. }\end{array}$ \\
\hline & & $\begin{array}{l}\text { España: León: Villar de } \\
\text { Santiago (León), III- } \\
\text { 1949. E. Morales }\end{array}$ & $\begin{array}{l}\text { MNCN_Ent } \\
24410 \overline{6}\end{array}$ & & $1.100 \mathrm{~m}$. & Macho & nuevo dato de localidad & $\begin{array}{l}\text { I.G. Undiano, } \\
2019 \text { det. }\end{array}$ \\
\hline & & $\begin{array}{l}\text { España: Lleida: Artiga } \\
\text { de Lin, 19-VIII-2008. } \\
\text { M. GaParís, N.P. Daniel, } \\
\text { G.G. Martín }\end{array}$ & $\begin{array}{l}\text { MNCN_Ent } \\
25498 \overline{5}\end{array}$ & & & Hembra & Alcohol & $\begin{array}{l}\text { I.G. Undiano, } \\
2019 \text { det. }\end{array}$ \\
\hline & & $\begin{array}{l}\text { España: Lleida: Artiga } \\
\text { de Lin, } 19 \text {-VIII-2008. } \\
\text { M. GaParis, N.P. Daniel, } \\
\text { G.G. Martin }\end{array}$ & $\begin{array}{l}\text { MNCN_Ent } \\
255006\end{array}$ & & & Macho & Alcohol & $\begin{array}{l}\text { I.G. Undiano, } \\
2019 \text { det. }\end{array}$ \\
\hline & & $\begin{array}{l}\text { España: Lleida: Baños } \\
\text { de Tredós (Lérida), VIII- } \\
\text { 1948. E. Morales // Exp. } \\
\text { Inst. de Entomología }\end{array}$ & $\begin{array}{l}\text { MNCN_Ent } \\
24414 \overline{1}\end{array}$ & & $1.695 \mathrm{~m}$. & Hembra & & $\begin{array}{l}\text { I.G. Undiano, } \\
2019 \text { det. }\end{array}$ \\
\hline & & $\begin{array}{l}\text { España: Lleida: } \\
\text { Bonaigua, sin datos. } \\
\text { M. Esc }\end{array}$ & $\begin{array}{l}\text { MNCN_Ent } \\
24413 \overline{7}\end{array}$ & & & Macho & & $\begin{array}{l}\text { I.G. Undiano, } \\
2019 \text { det. }\end{array}$ \\
\hline & & $\begin{array}{l}\text { España: Lleida: Esterri, } \\
\text { sin datos. M. Esc }\end{array}$ & $\begin{array}{l}\text { MNCN_Ent } \\
24413 \overline{6}\end{array}$ & & & Hembra & & $\begin{array}{l}\text { I.G. Undiano, } \\
2019 \text { det. }\end{array}$ \\
\hline & & $\begin{array}{l}\text { España: Lleida: Llanos } \\
\text { de Beret, Valle de Arán, } \\
\text { Prov. de Lérida, 2-VIII- } \\
\text { 1948. Exp. Inst. Esp. } \\
\text { Entomología }\end{array}$ & $\begin{array}{l}\text { MNCN_Ent } \\
24415 \overline{3}\end{array}$ & & & Hembra & & $\begin{array}{l}\text { I.G. Undiano, } \\
2019 \text { det. }\end{array}$ \\
\hline & & $\begin{array}{l}\text { España: Lleida: Ntra. } \\
\text { Sra. de las Aras } \\
\text { (Lérida), 26-VII-1948. } \\
\text { E. Morales // Exp. Inst. } \\
\text { Esp. Entomologia }\end{array}$ & $\begin{array}{l}\text { MNCN_Ent } \\
24414 \overline{8}\end{array}$ & & $1.652 \mathrm{~m}$. & Hembra & & $\begin{array}{l}\text { I.G. Undiano, } \\
2019 \text { det. }\end{array}$ \\
\hline & & $\begin{array}{l}\text { España: Lleida: Salardú, } \\
\text { Prov. de Lérida, VIII-48. } \\
\text { E. Morales // Exp. Inst. } \\
\text { Esp. Entomologia }\end{array}$ & $\begin{array}{l}\text { MNCN_Ent } \\
24414 \overline{9}\end{array}$ & & $1.260 \mathrm{~m}$. & Hembra & & $\begin{array}{l}\text { I.G. Undiano, } \\
2019 \text { det. }\end{array}$ \\
\hline & & $\begin{array}{l}\text { España: Lleida: Salardú, } \\
\text { Prov. de Lérida, VIII-48. } \\
\text { E. Morales // Exp. Inst. } \\
\text { Esp. Entomología }\end{array}$ & $\begin{array}{l}\text { MNCN_Ent } \\
244150^{-}\end{array}$ & & $1.260 \mathrm{~m}$. & Hembra & & $\begin{array}{l}\text { I.G. Undiano, } \\
2019 \text { det. }\end{array}$ \\
\hline & & $\begin{array}{l}\text { España: Lleida: Salardú, } \\
\text { Valle de Arán, Prov. } \\
\text { Lérida, sin datos. C. } \\
\text { Bolivar }\end{array}$ & $\begin{array}{l}\text { MNCN_Ent } \\
244151\end{array}$ & & & Hembra & & $\begin{array}{l}\text { I.G. Undiano, } \\
2019 \text { det. }\end{array}$ \\
\hline & & $\begin{array}{l}\text { España: Lleida: Salardú, } \\
\text { Valle de Arán, Prov. } \\
\text { Lérida, sin datos. C. } \\
\text { Bolivar }\end{array}$ & $\begin{array}{l}\text { MNCN Ent } \\
24415 \overline{2}\end{array}$ & & & Hembra & & $\begin{array}{l}\text { I.G. Undiano, } \\
2019 \text { det. }\end{array}$ \\
\hline & & $\begin{array}{l}\text { España: Lleida: Sierra } \\
\text { del Cadi, Agosto } 06 . \\
\text { Arias }\end{array}$ & $\begin{array}{l}\text { MNCN_Ent } \\
24414 \overline{2}\end{array}$ & & & Hembra & & $\begin{array}{l}\text { I.G. Undiano, } \\
2019 \text { det. }\end{array}$ \\
\hline & & $\begin{array}{l}\text { España: Lleida: Sierra } \\
\text { del Cadi, Agosto } 06 . \\
\text { Arias }\end{array}$ & $\begin{array}{l}\text { MNCN_Ent } \\
24414 \overline{3}\end{array}$ & & & Hembra & & $\begin{array}{l}\text { I.G. Undiano, } \\
2019 \text { det. }\end{array}$ \\
\hline & & $\begin{array}{l}\text { España: Lleida: Sierra } \\
\text { del Cadi, Agosto } 1906 . \\
\text { Arias }\end{array}$ & $\begin{array}{l}\text { MNCN_Ent } \\
24414 \overline{4}\end{array}$ & & & Hembra & & $\begin{array}{l}\text { I.G. Undiano, } \\
2019 \text { det. }\end{array}$ \\
\hline & & $\begin{array}{l}\text { España: Lleida: Sierra } \\
\text { del Cadi, Agosto } 06 . \\
\text { Arias }\end{array}$ & $\begin{array}{l}\text { MNCN_Ent } \\
24414 \overline{5}\end{array}$ & & & Macho & & $\begin{array}{l}\text { I.G. Undiano, } \\
2019 \text { det. }\end{array}$ \\
\hline & & $\begin{array}{l}\text { España: Lleida: Sierra } \\
\text { del Cadi, Agosto } 06 . \\
\text { Arias }\end{array}$ & $\begin{array}{l}\text { MNCN_Ent } \\
24414 \overline{6}\end{array}$ & & & Hembra & & $\begin{array}{l}\text { I.G. Undiano, } \\
2019 \text { det. }\end{array}$ \\
\hline
\end{tabular}




\begin{tabular}{|c|c|c|c|c|c|c|c|c|}
\hline FAMILIA & ESPECIE & DATOS DE CAPTURA & $\mathrm{N}^{\circ}$ CAT. & PROCEDENCIA & ALTITUD & SEXO & OBSERVACIONES & DETERMINADO \\
\hline \multirow[t]{23}{*}{ PANORPIDAE } & \multirow{23}{*}{$\begin{array}{l}\text { Panorpa } \\
\text { meridionalis } \\
\text { Rambur, } 1842\end{array}$} & $\begin{array}{l}\text { España: Lleida: Sierra del } \\
\text { Cadi, Agosto 06. Arias }\end{array}$ & $\begin{array}{l}\text { MNCN_Ent } \\
24414 \overline{7}\end{array}$ & & & Hembra & & $\begin{array}{l}\text { I.G. Undiano, } \\
2019 \text { det. }\end{array}$ \\
\hline & & $\begin{array}{l}\text { España: Lleida: Urdós, } \\
\text { 20-VII-905. Bolivar }\end{array}$ & $\begin{array}{l}\text { MNCN_Ent } \\
24413 \overline{8}\end{array}$ & & & Hembra & & $\begin{array}{l}\text { I.G. Undiano, } \\
2019 \text { det. }\end{array}$ \\
\hline & & $\begin{array}{l}\text { España: Madrid: C. Viejo, } \\
\text { Madrid, 20-V-1990. C. } \\
\text { Martín }\end{array}$ & $\begin{array}{l}\text { MNCN_Ent } \\
24406 \overline{5}\end{array}$ & & & Hembra & & $\begin{array}{l}\text { I.G. Undiano, } \\
2019 \text { det. }\end{array}$ \\
\hline & & $\begin{array}{l}\text { España: Madrid: } \\
\text { Cercedilla (Madrid) } \\
\text { Museo, sin datos. sin } \\
\text { datos }\end{array}$ & $\begin{array}{l}\text { MNCN_Ent } \\
24407 \overline{2}\end{array}$ & & & Hembra & $\begin{array}{l}\text { Etiqueta: Panorpa meridionalis Rb. Navás } \\
\text { S.J. det. }\end{array}$ & $\begin{array}{l}\text { I.G. Undiano, } \\
2019 \text { det. }\end{array}$ \\
\hline & & $\begin{array}{l}\text { España: Madrid: } \\
\text { Cercedilla, 20-VI-13. } \\
\text { sin datos }\end{array}$ & $\begin{array}{l}\text { MNCN_Ent } \\
24407 \overline{3}\end{array}$ & & & Hembra & $\begin{array}{l}\text { Etiqueta: Panorpa meridionalis Rb. Navás } \\
\text { S.J. det. }\end{array}$ & $\begin{array}{l}\text { I.G. Undiano, } \\
2019 \text { det. }\end{array}$ \\
\hline & & $\begin{array}{l}\text { España: Madrid: El } \\
\text { Escorial, } 22 \text { Mayo } 1904 . \\
\text { G. Mercet }\end{array}$ & $\begin{array}{l}\text { MNCN_Ent } \\
244062\end{array}$ & & & Hembra & & $\begin{array}{l}\text { I.G. Undiano, } \\
2019 \text { det. }\end{array}$ \\
\hline & & $\begin{array}{l}\text { España: Madrid: El } \\
\text { Escorial, sin datos. } \\
\text { Laguna }\end{array}$ & $\begin{array}{l}\text { MNCN_Ent } \\
244060\end{array}$ & & & Hembra & & $\begin{array}{l}\text { I.G. Undiano, } \\
2019 \text { det. }\end{array}$ \\
\hline & & $\begin{array}{l}\text { España: Madrid: Escorial, } \\
\text { sin datos. Arias }\end{array}$ & $\begin{array}{l}\text { MNCN_Ent } \\
244061\end{array}$ & & & Macho & & $\begin{array}{l}\text { I.G. Undiano, } \\
2019 \text { det. }\end{array}$ \\
\hline & & $\begin{array}{l}\text { España: Madrid: Escorial, } \\
\text { 15-V-909. G. Mercet }\end{array}$ & $\begin{array}{l}\text { MNCN_Ent } \\
24405 \overline{8}\end{array}$ & & & Hembra & & $\begin{array}{l}\text { I.G. Undiano, } \\
2019 \text { det. }\end{array}$ \\
\hline & & $\begin{array}{l}\text { España: Madrid: Escorial, } \\
\text { sin datos. F. Escalera }\end{array}$ & $\begin{array}{l}\text { MNCN_Ent } \\
24405 \overline{9}\end{array}$ & & & Hembra & & $\begin{array}{l}\text { I.G. Undiano, } \\
2019 \text { det. }\end{array}$ \\
\hline & & $\begin{array}{l}\text { España: Madrid: Las } \\
\text { Zorreras, El Escorial } \\
\text { (Madrid), 28-Vl-1995. F. } \\
\text { Fer. Rubio }\end{array}$ & $\begin{array}{l}\text { MNCN_Ent } \\
24406 \overline{3}\end{array}$ & & & Macho & & $\begin{array}{l}\text { I.G. Undiano, } \\
2019 \text { det. }\end{array}$ \\
\hline & & $\begin{array}{l}\text { España: Madrid: Lozoya, } \\
\text { Jun. Mazarr. }\end{array}$ & $\begin{array}{l}\text { MNCN_Ent } \\
244069\end{array}$ & $\begin{array}{l}\text { Col. Mazarr- } \\
\text { Bolivar [Colección } \\
\text { Mazarredo } \\
\text { Bolivar] }\end{array}$ & & Hembra & & $\begin{array}{l}\text { I.G. Undiano, } \\
2019 \text { det. }\end{array}$ \\
\hline & & $\begin{array}{l}\text { España: Madrid: Lozoya, } \\
\text { Junio. Mazarr. }\end{array}$ & $\begin{array}{l}\text { MNCN_Ent } \\
24407 \overline{0}\end{array}$ & $\begin{array}{l}\text { Col. Mazarr- } \\
\text { Bolívar [Colección } \\
\text { Mazarredo } \\
\text { Bolívar] }\end{array}$ & & Macho & & $\begin{array}{l}\text { I.G. Undiano, } \\
2019 \text { det. }\end{array}$ \\
\hline & & $\begin{array}{l}\text { España: Madrid: Lozoya, } \\
\text { Jun. Mazarr. }\end{array}$ & $\begin{array}{l}\text { MNCN_Ent } \\
244080\end{array}$ & $\begin{array}{l}\text { Col. Mazarr- } \\
\text { Bolivar [Colección } \\
\text { Mazarredo } \\
\text { Bolivar] }\end{array}$ & & Hembra & & $\begin{array}{l}\text { I.G. Undiano, } \\
2019 \text { det. }\end{array}$ \\
\hline & & $\begin{array}{l}\text { España: Madrid: Lozoya, } \\
\text { sin datos. F. Navarro }\end{array}$ & $\begin{array}{l}\text { MNCN_Ent } \\
24406 \overline{8}\end{array}$ & & & Hembra & & $\begin{array}{l}\text { I.G. Undiano, } \\
2019 \text { det. }\end{array}$ \\
\hline & & $\begin{array}{l}\text { España: Madrid: Lozoya, } \\
\text { sin datos. F. Navarro }\end{array}$ & $\begin{array}{l}\text { MNCN_Ent } \\
244071^{-}\end{array}$ & & & Hembra & & $\begin{array}{l}\text { I.G. Undiano, } \\
2019 \text { det. }\end{array}$ \\
\hline & & $\begin{array}{l}\text { España: Madrid: Montejo } \\
\text { de la Sierra, Vl-1936. D. } \\
\text { Peláez }\end{array}$ & $\begin{array}{l}\text { MNCN_Ent } \\
244067\end{array}$ & & & Hembra & & $\begin{array}{l}\text { I.G. Undiano, } \\
2019 \text { det. }\end{array}$ \\
\hline & & $\begin{array}{l}\text { España: Madrid: Paular, } \\
20 \text { Junio. Mazarredo }\end{array}$ & $\begin{array}{l}\text { MNCN_Ent } \\
24406 \overline{4}\end{array}$ & $\begin{array}{l}\text { Col. Mazar - } \\
\text { Boliv [Colección } \\
\text { Mazarredo } \\
\text { Bolivar] }\end{array}$ & & Hembra & $\begin{array}{l}\text { Etiqueta: Panorpa meridionalis Ramb. } \\
\text { [manuscrita, aparentemente de Navás] }\end{array}$ & $\begin{array}{l}\text { I.G. Undiano, } \\
2019 \text { det. }\end{array}$ \\
\hline & & $\begin{array}{l}\text { España: Madrid: Pto. de } \\
\text { la Morcuera, Madrid, 21- } \\
\text { V-1994. F. Fernández- } \\
\text { Rubio }\end{array}$ & $\begin{array}{l}\text { MNCN_Ent } \\
24406 \overline{6}\end{array}$ & & & Hembra & & $\begin{array}{l}\text { I.G. Undiano, } \\
2019 \text { det. }\end{array}$ \\
\hline & & $\begin{array}{l}\text { España: Pontevedra: } \\
\text { Cangas, sin datos. Flores }\end{array}$ & $\begin{array}{l}\text { MNCN_Ent } \\
244112\end{array}$ & & & Hembra & nuevo dato de localidad & $\begin{array}{l}\text { I.G. Undiano, } \\
2019 \text { det. }\end{array}$ \\
\hline & & $\begin{array}{l}\text { España: Segovia: } \\
\text { Balsain, sin datos. J. } \\
\text { Abajo }\end{array}$ & $\begin{array}{l}\text { MNCN_Ent } \\
244081\end{array}$ & & & Hembra & & $\begin{array}{l}\text { I.G. Undiano, } \\
2019 \text { det. }\end{array}$ \\
\hline & & $\begin{array}{l}\text { España: Segovia: } \\
\text { Balsain, sin datos. J. } \\
\text { Abajo. }\end{array}$ & $\begin{array}{l}\text { MNCN_Ent } \\
24408 \overline{2}\end{array}$ & & & Hembra & & $\begin{array}{l}\text { I.G. Undiano, } \\
2019 \text { det. }\end{array}$ \\
\hline & & $\begin{array}{l}\text { España: Segovia: } \\
\text { Balsain, sin datos. C. } \\
\text { Bolivar }\end{array}$ & $\begin{array}{l}\text { MNCN_Ent } \\
24408 \overline{4}\end{array}$ & & & Macho & $\begin{array}{l}\text { Etiqueta: Panorpa meridionalis Rb. Navás } \\
\text { S.J. det. }\end{array}$ & $\begin{array}{l}\text { I.G. Undiano, } \\
2019 \text { det. }\end{array}$ \\
\hline
\end{tabular}




\begin{tabular}{|c|c|c|c|c|c|c|c|c|}
\hline FAMILIA & ESPECIE & DATOS DE CAPTURA & $\mathrm{N}^{\circ}$ CAT. & PROCEDENCIA & ALTITUD & SEXO & OBSERVACIONES & DETERMINADO \\
\hline \multirow[t]{20}{*}{ PANORPIDAE } & $\begin{array}{l}\text { Panorpa } \\
\text { meridionalis } \\
\text { Rambur, } 1842\end{array}$ & $\begin{array}{l}\text { España: Segovia: } \\
\text { Balsain, Prov. de } \\
\text { Segovia, VII-1932. F. } \\
\text { Escalera }\end{array}$ & $\begin{array}{l}\text { MNCN_Ent } \\
24408 \overline{3}\end{array}$ & & & Hembra & & $\begin{array}{l}\text { I.G. Undiano, } \\
2019 \text { det. }\end{array}$ \\
\hline & & $\begin{array}{l}\text { España: Segovia: } \\
\text { Balsain, Prov. de } \\
\text { Segovia, VII-1932. F. } \\
\text { Escalera }\end{array}$ & $\begin{array}{l}\text { MNCN_Ent } \\
244085\end{array}$ & & & Hembra & & $\begin{array}{l}\text { I.G. Undiano, } \\
2019 \text { det. }\end{array}$ \\
\hline & & $\begin{array}{l}\text { España: Segovia: } \\
\text { Granja, Julio!. sin datos }\end{array}$ & $\begin{array}{l}\text { MNCN_Ent } \\
24408 \overline{6}\end{array}$ & & & & $\begin{array}{l}\text { Etiqueta: Panorpa meridionalis Ramb. } \\
\text { [manuscrita, aparentemente de Navás] }\end{array}$ & $\begin{array}{l}\text { I.G. Undiano, } \\
2019 \text { det. }\end{array}$ \\
\hline & & $\begin{array}{l}\text { España: Segovia: S. } \\
\text { Ildefonso, VII-1906. } \\
\text { Escalera }\end{array}$ & $\begin{array}{l}\text { MNCN_Ent } \\
244075\end{array}$ & & & Hembra & & $\begin{array}{l}\text { I.G. Undiano, } \\
2019 \text { det. }\end{array}$ \\
\hline & & $\begin{array}{l}\text { España: Segovia: S. } \\
\text { Ildefonso, VIl-1906. } \\
\text { Escalera }\end{array}$ & $\begin{array}{l}\text { MNCN_Ent } \\
244076\end{array}$ & & & Hembra & & $\begin{array}{l}\text { I.G. Undiano, } \\
2019 \text { det. }\end{array}$ \\
\hline & & $\begin{array}{l}\text { España: Segovia: S. } \\
\text { Ildefonso, VIl-1906. } \\
\text { Escalera }\end{array}$ & $\begin{array}{l}\text { MNCN_Ent } \\
244077\end{array}$ & & & Macho & & $\begin{array}{l}\text { I.G. Undiano, } \\
2019 \text { det. }\end{array}$ \\
\hline & & $\begin{array}{l}\text { España: Segovia: S. } \\
\text { Ildefonso, VIl-1906. } \\
\text { Escalera }\end{array}$ & $\begin{array}{l}\text { MNCN_Ent } \\
244078\end{array}$ & & & Macho & & $\begin{array}{l}\text { I.G. Undiano, } \\
2019 \text { det. }\end{array}$ \\
\hline & & $\begin{array}{l}\text { España: Segovia: S. } \\
\text { Ildefonso, VII-1906. } \\
\text { Escalera }\end{array}$ & $\begin{array}{l}\text { MNCN_Ent } \\
24407 \overline{4}\end{array}$ & & & Hembra & & $\begin{array}{l}\text { I.G. Undiano, } \\
2019 \text { det. }\end{array}$ \\
\hline & & $\begin{array}{l}\text { España: Segovia: S. } \\
\text { Ildefonso, VIII-1931. M. } \\
\text { Bohigas }\end{array}$ & $\begin{array}{l}\text { MNCN_Ent } \\
244079\end{array}$ & & & Macho & & $\begin{array}{l}\text { I.G. Undiano, } \\
2019 \text { det. }\end{array}$ \\
\hline & & $\begin{array}{l}\text { España: Teruel: } \\
\text { Bronchales, Prov. de } \\
\text { Teruel, VIII-1932. M. } \\
\text { Escalera }\end{array}$ & $\begin{array}{l}\text { MNCN_Ent } \\
244113\end{array}$ & & & Macho & & $\begin{array}{l}\text { I.G. Undiano, } \\
2019 \text { det. }\end{array}$ \\
\hline & & $\begin{array}{l}\text { Francia: Alp. Pyr, sin } \\
\text { datos. sin datos }\end{array}$ & $\begin{array}{l}\text { MNCN_Ent } \\
244170\end{array}$ & $\begin{array}{l}\text { Coll. Seebold, } \\
\text { Mus. Madrid }\end{array}$ & & Hembra & & $\begin{array}{l}\text { I.G. Undiano, } \\
2019 \text { det. }\end{array}$ \\
\hline & & $\begin{array}{l}\text { Francia: Alp. Pyr, sin } \\
\text { datos. sin datos }\end{array}$ & $\begin{array}{l}\text { MNCN_Ent } \\
244171\end{array}$ & $\begin{array}{l}\text { Coll. Seebold, } \\
\text { Mus. Madrid }\end{array}$ & & Hembra & & $\begin{array}{l}\text { I.G. Undiano, } \\
2019 \text { det. }\end{array}$ \\
\hline & & $\begin{array}{l}\text { Francia: Ariège/ } \\
\text { Pyrénées-Orientales: } \\
\text { Pyr. Orient., Le Vernet, } \\
\text { VII-94. sin datos }\end{array}$ & $\begin{array}{l}\text { MNCN_Ent } \\
24416 \overline{3}\end{array}$ & $\begin{array}{l}\text { Coll. Seebold, } \\
\text { Mus. Madrid }\end{array}$ & & Hembra & & $\begin{array}{l}\text { I.G. Undiano, } \\
2019 \text { det. }\end{array}$ \\
\hline & & $\begin{array}{l}\text { Francia: Ariège/ } \\
\text { Pyrénées-Orientales: } \\
\text { Pyr. Orient., Le Vernet, } \\
\text { VII-94. sin datos }\end{array}$ & $\begin{array}{l}\text { MNCN_Ent } \\
24416 \overline{4}\end{array}$ & $\begin{array}{l}\text { Coll. Seebold, } \\
\text { Mus. Madrid }\end{array}$ & & Hembra & & $\begin{array}{l}\text { I.G. Undiano, } \\
2019 \text { det. }\end{array}$ \\
\hline & & $\begin{array}{l}\text { Francia: Ariège/ } \\
\text { Pyrénées-Orientales: } \\
\text { Pyr. Orient., Le Vernet, } \\
\text { VII-94. sin datos }\end{array}$ & $\begin{array}{l}\text { MNCN_Ent } \\
24416 \overline{5}\end{array}$ & $\begin{array}{l}\text { Coll. Seebold, } \\
\text { Mus. Madrid }\end{array}$ & & Hembra & & $\begin{array}{l}\text { I.G. Undiano, } \\
2019 \text { det. }\end{array}$ \\
\hline & & $\begin{array}{l}\text { Francia: Ariège/ } \\
\text { Pyrénées-Orientales: } \\
\text { Pyr. Orient., Le Vernet, } \\
\text { VII-94. sin datos }\end{array}$ & $\begin{array}{l}\text { MNCN_Ent } \\
244166\end{array}$ & $\begin{array}{l}\text { Coll. Seebold, } \\
\text { Mus. Madrid }\end{array}$ & & Hembra & & $\begin{array}{l}\text { I.G. Undiano, } \\
2019 \text { det. }\end{array}$ \\
\hline & & $\begin{array}{l}\text { Francia: Ariège: Ariege, } \\
\text { Francia, sin datos. Prats }\end{array}$ & $\begin{array}{l}\text { MNCN_Ent } \\
24416 \overline{7}\end{array}$ & & & Hembra & & $\begin{array}{l}\text { I.G. Undiano, } \\
2019 \text { det. }\end{array}$ \\
\hline & & $\begin{array}{l}\text { Francia: Ariège: Mijanès, } \\
\text { 19-VI-2013. M. GaParis, } \\
\text { N.P. Daniel, G.G. Martin }\end{array}$ & $\begin{array}{l}\text { MNCN_Ent } \\
254982\end{array}$ & & $1.170 \mathrm{~m}$ & Macho & Alcohol & $\begin{array}{l}\text { I.G. Undiano, } \\
2019 \text { det. }\end{array}$ \\
\hline & & $\begin{array}{l}\text { Francia: Haute- } \\
\text { Garonne: } 6 \text { km NE } \\
\text { Aspet, Haute-Garonne } \\
\text { (Francia), 23-VIII-2008. } \\
\text { M. Ga-Paris }\end{array}$ & $\begin{array}{l}\text { MNCN_Ent } \\
74663\end{array}$ & & & Hembra & & $\begin{array}{l}\text { I.G. Undiano, } \\
2019 \text { det. }\end{array}$ \\
\hline & & $\begin{array}{l}\text { Francia: Haute- } \\
\text { Garonne: } 6 \text { km al } \\
\text { noreste de Aspet, 23- } \\
\text { VIII-2008. M. GaParis, } \\
\text { N.P. Daniel, G.G. Martin }\end{array}$ & $\begin{array}{l}\text { MNCN_Ent } \\
254983\end{array}$ & & & Hembra & Alcohol & $\begin{array}{l}\text { I.G. Undiano, } \\
2019 \text { det. }\end{array}$ \\
\hline
\end{tabular}




\begin{tabular}{|c|c|c|c|c|c|c|c|c|}
\hline FAMILIA & ESPECIE & DATOS DE CAPTURA & $\mathrm{N}^{\circ}$ CAT. & PROCEDENCIA & ALTITUD & SEXO & OBSERVACIONES & DETERMINADO \\
\hline \multirow[t]{19}{*}{ PANORPIDAE } & $\begin{array}{l}\text { Panorpa } \\
\text { meridionalis } \\
\text { Rambur, } 1842\end{array}$ & $\begin{array}{l}\text { Francia: Haute- } \\
\text { Garonne: } 6 \text { km al } \\
\text { noreste de Aspet, 23- } \\
\text { VIII-2008. M. GaParis, } \\
\text { N.P. Daniel, G.G. Martín }\end{array}$ & $\begin{array}{l}\text { MNCN_Ent } \\
254984\end{array}$ & & & Hembra & Alcohol & $\begin{array}{l}\text { I.G. Undiano, } \\
2019 \text { det. }\end{array}$ \\
\hline & & $\begin{array}{l}\text { Francia: Haute-Garonne } \\
\text { Arguenos, } 21-V I I I-2008 . \\
\text { M. GaParís, N.P. Daniel, } \\
\text { G.G. Martín }\end{array}$ & $\begin{array}{l}\text { MNCN_Ent } \\
254989\end{array}$ & & & Hembra & Alcohol & $\begin{array}{l}\text { I.G. Undiano, } \\
2019 \text { det. }\end{array}$ \\
\hline & & $\begin{array}{l}\text { Francia: Haute-Garonne } \\
\text { Arguenos, } 21-V I I I-2008 . \\
\text { M. Ga'París, N.P. Daniel, } \\
\text { G.G. Martín }\end{array}$ & $\begin{array}{l}\text { MNCN_Ent } \\
254990\end{array}$ & & & Hembra & Alcohol & $\begin{array}{l}\text { I.G. Undiano, } \\
2019 \text { det. }\end{array}$ \\
\hline & & $\begin{array}{l}\text { Francia: Haute-Garonne } \\
\text { Arguenos, 30-VIII-2008. } \\
\text { M. GaParís, N.P. Daniel, } \\
\text { G.G. Martín }\end{array}$ & $\begin{array}{l}\text { MNCN_Ent } \\
25500 \overline{5}\end{array}$ & & & Macho & Alcohol & $\begin{array}{l}\text { I.G. Undiano, } \\
2019 \text { det. }\end{array}$ \\
\hline & & $\begin{array}{l}\text { Francia: Haute- } \\
\text { Garonne: Juzet-d'Izaut, } \\
\text { 20-VIII-2008. M. } \\
\text { G'París, N.P. Daniel, } \\
\text { G.G. Martín }\end{array}$ & $\begin{array}{l}\text { MNCN_Ent } \\
255009\end{array}$ & & & Macho & Alcohol & $\begin{array}{l}\text { I.G. Undiano, } \\
2019 \text { det. }\end{array}$ \\
\hline & & $\begin{array}{l}\text { Francia: Hautes- } \\
\text { Pyrénées, Cautarets, } \\
\text { Juillet 1894. T. Seebold }\end{array}$ & $\begin{array}{l}\text { MNCN_Ent } \\
24416 \overline{8}\end{array}$ & $\begin{array}{l}\text { Coll. Seebold, } \\
\text { Mus. Madrid }\end{array}$ & & Hembra & & $\begin{array}{l}\text { I.G. Undiano, } \\
2019 \text { det. }\end{array}$ \\
\hline & & $\begin{array}{l}\text { Francia: Hautes- } \\
\text { Pyrénées, Cautarets, } \\
\text { Juillet 1894. T. Seebold }\end{array}$ & $\begin{array}{l}\text { MNCN_Ent } \\
24416 \overline{9}\end{array}$ & $\begin{array}{l}\text { Coll. Seebold, } \\
\text { Mus. Madrid }\end{array}$ & & Hembra & & $\begin{array}{l}\text { I.G. Undiano, } \\
2019 \text { det. }\end{array}$ \\
\hline & & $\begin{array}{l}\text { Francia: Pyrénées- } \\
\text { Orientales: Fillols, } \\
\text { Mont Canigou, 22-IX- } \\
\text { 2009. J.G. Rodríguez }\end{array}$ & $\begin{array}{l}\text { MNCN_Ent } \\
25500 \overline{2}\end{array}$ & & $848 \mathrm{~m}$. & Hembra & Alcohol & $\begin{array}{l}\text { I.G. Undiano, } \\
2019 \text { det. }\end{array}$ \\
\hline & & $\begin{array}{l}\text { Francia: Pyrénées- } \\
\text { Orientales: Fillols, } \\
\text { Mont Canigou, 22-IX- } \\
\text { 2009. J.G. Rodriguez }\end{array}$ & $\begin{array}{l}\text { MNCN_Ent } \\
25500 \overline{3}\end{array}$ & & $848 \mathrm{~m}$. & Hembra & Alcohol & $\begin{array}{l}\text { I.G. Undiano, } \\
2019 \text { det. }\end{array}$ \\
\hline & & $\begin{array}{l}\text { Francia: Pyrénées- } \\
\text { Orientales: Fillols, } \\
\text { Mont Canigou, 22-IX- } \\
\text { 2009. J.G. Rodríguez }\end{array}$ & $\begin{array}{l}\text { MNCN_Ent } \\
25500 \overline{4}\end{array}$ & & $848 \mathrm{~m}$. & Hembra & Alcohol & $\begin{array}{l}\text { I.G. Undiano, } \\
2019 \text { det. }\end{array}$ \\
\hline & & $\begin{array}{l}\text { Francia: Pyrénées- } \\
\text { Orientales: Prats de } \\
\text { Mollo, 3-VIl-2011. M. } \\
\text { GaParís, V. DeJesús, P. } \\
\text { Pavón }\end{array}$ & $\begin{array}{l}\text { MNCN_Ent } \\
254960\end{array}$ & & $1.175 \mathrm{~m}$. & Macho & Alcohol & $\begin{array}{l}\text { I.G. Undiano, } \\
2019 \text { det. }\end{array}$ \\
\hline & & $\begin{array}{l}\text { Portugal: Évora: } \\
\text { Redondo: } 9 \text { km al oeste } \\
\text { de Redondo, 26-III- } \\
\text { 2012. I.M. Solano, J.G. } \\
\text { Rodríguez, E.R. Gil }\end{array}$ & $\begin{array}{l}\text { MNCN_Ent } \\
254980\end{array}$ & & $233 \mathrm{~m}$. & Macho & Alcohol & $\begin{array}{l}\text { I.G. Undiano, } \\
2019 \text { det. }\end{array}$ \\
\hline & & $\begin{array}{l}\text { Portugal: Viseu: NO } \\
\text { Viseu: Covas do Rio, } \\
\text { 17-VII-2007. M. GaParis }\end{array}$ & $\begin{array}{l}\text { MNCN_Ent } \\
254991\end{array}$ & & & Hembra & Alcohol & $\begin{array}{l}\text { I.G. Undiano, } \\
2019 \text { det. }\end{array}$ \\
\hline & & $\begin{array}{l}\text { Suiza: Valais: Valais, sin } \\
\text { datos. sin datos }\end{array}$ & $\begin{array}{l}\text { MNCN_Ent } \\
24417 \overline{3}\end{array}$ & $\begin{array}{l}\text { Coll. Seebold, } \\
\text { Mus. Madrid }\end{array}$ & & Hembra & & $\begin{array}{l}\text { I.G. Undiano, } \\
2019 \text { det. }\end{array}$ \\
\hline & $\begin{array}{l}\text { Panorpa } \\
\text { rufescens } \\
\text { Rambur, } 1842\end{array}$ & $\begin{array}{l}\text { Estados Unidos: Nueva } \\
\text { York: Ithaca, N. Y., 15- } \\
\text { VIII-1928. C. Bolivar }\end{array}$ & $\begin{array}{l}\text { MNCN_Ent } \\
24420 \overline{4}\end{array}$ & & & Macho & & $\begin{array}{l}\text { I.G. Undiano, } \\
2019 \text { det. }\end{array}$ \\
\hline & & $\begin{array}{l}\text { Estados Unidos: Nueva } \\
\text { York: Ithaca, N. Y., } \\
\text { Estados Unidos, 18-VIII- } \\
\text { 1928. C. Bolivar }\end{array}$ & $\begin{array}{l}\text { MNCN_Ent } \\
24420 \overline{3}\end{array}$ & & & Macho & & $\begin{array}{l}\text { I.G. Undiano, } \\
2019 \text { det. }\end{array}$ \\
\hline & $\begin{array}{l}\text { Panorpa } \\
\text { vulgaris Imhoff } \\
\& \text { Labram, }\end{array}$ & $\begin{array}{l}\text { España: Pontevedra: } \\
\text { Catoira, 14-VI-2018. R. } \\
\text { González }\end{array}$ & $\begin{array}{l}\text { MNCN_Ent } \\
25497 \overline{8}\end{array}$ & & & Hembra & Alcohol, nuevo dato de localidad & $\begin{array}{l}\text { I.G. Undiano, } \\
2019 \text { det. }\end{array}$ \\
\hline & 1845 & $\begin{array}{l}\text { Francia: Ariège: Mijanès, } \\
\text { 19-VI-2013. M. GaParís, } \\
\text { N.P. Daniel, G.G. Martín }\end{array}$ & $\begin{array}{l}\text { MNCN_Ent } \\
254981\end{array}$ & & $1.170 \mathrm{~m}$. & Hembra & Alcohol & $\begin{array}{l}\text { I.G. Undiano, } \\
2019 \text { det. }\end{array}$ \\
\hline & & $\begin{array}{l}\text { Hungria: Veszprém: } \\
\text { Németbánya, 16-VII- } \\
\text { 2011. M. G'París, J. } \\
\text { Vörös }\end{array}$ & $\begin{array}{l}\text { MNCN_Ent } \\
254964\end{array}$ & & $344 \mathrm{~m}$. & Hembra & Alcohol & $\begin{array}{l}\text { I.G. Undiano, } \\
2019 \text { det. }\end{array}$ \\
\hline
\end{tabular}




\begin{tabular}{|c|c|c|c|c|c|c|c|c|}
\hline FAMILIA & ESPECIE & DATOS DE CAPTURA & N CAT. & PROCEDENCIA & ALTITUD & SEXO & OBSERVACIONES & DETERMINADO \\
\hline \multirow[t]{4}{*}{ PANORPIDAE } & $\begin{array}{l}\text { Panorpa } \\
\text { vulgaris Imhoff } \\
\text { \& Labram, } \\
1845\end{array}$ & $\begin{array}{l}\text { Hungria: Veszprém: } \\
\text { Németbánya, 16-VII- } \\
\text { 2011. M. GaParís, J. } \\
\text { Vörös }\end{array}$ & $\begin{array}{l}\text { MNCN_Ent } \\
25496 \overline{6}\end{array}$ & & $344 \mathrm{~m}$. & Hembra & Alcohol & $\begin{array}{l}\text { I.G. Undiano, } \\
2019 \text { det. }\end{array}$ \\
\hline & $\begin{array}{l}\text { Panorpa } \\
\text { Linnaeus, } \\
1758\end{array}$ & $\begin{array}{l}\text { Japón: Kyoto: Shishen- } \\
\text { dò (camino forestal), sin } \\
\text { datos. M. GaParis }\end{array}$ & $\begin{array}{l}\text { MNCN_Ent } \\
255011\end{array}$ & & & Hembra & Alcohol & $\begin{array}{l}\text { I.G. Undiano, } \\
2019 \text { det. }\end{array}$ \\
\hline & & $\begin{array}{l}\text { Japón: Kyoto: Shishen- } \\
\text { dò (camino forestal), sin } \\
\text { datos. M. GaParis }\end{array}$ & $\begin{array}{l}\text { MNCN_Ent } \\
255012\end{array}$ & & & Hembra & Alcohol & $\begin{array}{l}\text { I.G. Undiano, } \\
2019 \text { det. }\end{array}$ \\
\hline & & $\begin{array}{l}\text { Japón: Kyoto: Shishen- } \\
\text { dō (camino forestal), sin } \\
\text { datos. M. GaParís }\end{array}$ & $\begin{array}{l}\text { MNCN_Ent } \\
25501 \overline{3}\end{array}$ & & & Macho & Alcohol & $\begin{array}{l}\text { I.G. Undiano, } \\
2019 \text { det. }\end{array}$ \\
\hline
\end{tabular}

Un ejemplar destacable de la colección es una hembra de $B$. aequalis, con etiqueta blanca impresa en letras rojas 'Cotype', siendo este tipo de etiqueta habitual en la colección del Muséum national d'Histoire naturelle de París. La especie fue descrita por Navás (1914), quien estudió los ejemplares que se recogieron en una expedición realizada años antes al África Oriental. En esta publicación aparece una descripción detallada del macho tipo de la especie, con localidad 'Landjoro, 900 m'. El ejemplar de la colección se encuentra etiquetado como cotipo (categoría utilizada antiguamente para referirse a un sintipo o paratipo) (CINZ, 2000). No obstante, no coinciden ni la localidad ni el sexo de éste (hembra de 'Taveta, $750 \mathrm{~m}$ ') con los datos que figuran en la descripción original del taxón. Esta hembra procede indudablemente de la misma expedición de 1911 a 1912 de Alluaud y Jeannel, junto con otros ejemplares que se encuentran en el Museo de París (Byers, 1971), desde donde nos han confirmado (Dr. André Nel, com. pers.) que, aparte del ejemplar tipo, hay otros tres ejemplares identificados por Navás, que según Byers (1971) serían dos machos y una hembra. Además, solo el holotipo está etiquetado como tal. Por tanto, el ejemplar hembra de $B$. aequalis de la colección carece de la condición de tipo, a pesar de su etiquetado.

Panorpa meridionalis es la especie con la distribución más amplia en la península ibérica, mientras que las demás especies de la familia Panorpidae, como $P$. communis y $P$. germanica, están más restringidas a la zona Eurosiberiana. Muchas de las localidades en las que se recogieron los ejemplares de la colección aportan nuevos datos a los ya registrados (Monserrat \& Tillier, 2013; BV, 2019; GBIF.org, 2019), como, por ejemplo, las citas de León para $P$. communis.

Los ejemplares de $P$. meridionalis con números de catálogo MNCN_Ent 244170 y MNCN_Ent 244171 (Tabla 2) presentan en su etiqueta de localidad las siglas: Alp. Pyr. Esto puede dar lugar a confusión puesto que no ha sido posible deducir la procedencia de los ejemplares. Otros especímenes que presentan dudas son los catalogados MNCN_Ent 244163 a MNCN_Ent 244166. En la etiqueta pone que se recogieron en la localidad de Le Vernet, Pyr. Orient. Sin embargo, Le Vernet es una comuna del departamento de Ariège $\mathrm{y}$ en el departamento de Pyrénées-Orientales se encuentra la localidad Vernet-les-Bains. Creemos que los ejemplares proceden de Vernet-les-Bains, del departamento de Pyrénées-Orientales, ya que Pyr. Orient. está indicado en la etiqueta y en esa localidad se pueden encontrar un balneario y varios hoteles, construidos en el siglo XIX.

La Colección de Entomología del MNCN cuenta con una gran representación de ejemplares paleárticos no ibéricos debido al material histórico que aportaron Theodor Seebold y Longinos Navás principalmente en lo que respecta a la colección en seco, y al reciente ingreso, ya mencionado, de material conservado en alcohol. De este último, los tres ejemplares japoneses de Panorpa extienden los registros a Asia, donde la diversidad de mecópteros es muy elevada en comparación con la Península y el resto del territorio europeo. Sin embargo, no han podido ser identificados a nivel de especie debido a que la última revisión del grupo para esa zona fue hecha por Miyake (1908), hay especies descritas con posterioridad y conseguir toda la bibliografía al respecto excede del objetivo de este trabajo.

Con esta revisión se pone de manifiesto la importancia de aportar nuevo material a las colecciones, donde se preservará y estará accesible a la comunidad científica para su estudio. También es relevante dar a conocer el contenido de los fondos, que aporta un incremento del conocimiento sobre la colección y el grupo de estudio, especialmente en casos como el que presentamos donde prácticamente el material había permanecido sin consultar desde hace un siglo.

\section{Agradecimientos}

Queremos agradecer al Dr. Mario García París y a la Dra. Carmen Rey del Castillo la cesión de sus ejemplares, que han incrementado en cantidad y calidad los fondos de la Colección de Entomología. También al Dr. André Nel (Muséum national d'Histoire naturelle, París), que nos ha confirmado la presencia de los ejemplares estudiados por Navás en su institución, y ha aclarado el etiquetado del material tipo. A Arabia Sánchez Terrón, responsable del laboratorio de preparación de muestras zoológicas, por su ayuda en la captura de las imágenes de las genitalias. A Manuel Sánchez Ruiz, por una primera revisión crítica que ha mejorado sustancialmente este trabajo, e igualmente a los revisores del manuscrito por sus acertados comentarios. 


\section{Referencias}

Allioni, C., 1766. Manipulus insectorum taurinensium. Mélanges de philosophie et de mathématique de la Société royale de Turin, 3: 185-198.

BV (Biodiversidad Virtual), 2019. Insectarium Virtual. Género Panorpa. Disponible en https://www.biodiversidadvirtual.org/insectarium/Genero-Panorpa-Linnaeus1758-cat22626.html (último acceso: 24 Jul. 2020).

Byers, G. W., 1971. An illustrated, annotated catalogue of African Mecoptera. The University of Kansas science bulletin, 49: 389-436.

Carpenter, F. M., 1930. The Lower Permian insects of Kansas. Part I. Introduction and the order Mecoptera. Bulletin of the Museum of Comparative Zoology, 52: 69101. Disponible en https://www.biodiversitylibrary.org/ part/93293\#/summary (último acceso: 9 Sep. 2020).

CINZ, 2000. Código Internacional de Nomenclatura Zoológica. Cuarta edición. Edición en español. International Trust for Zoological Nomenclature. Madrid, xxix + 156 pp. Disponible en http://www.sam.mncn.csic.es/codigo.pdf (último acceso: 24 Jul. 2020).

Esben-Petersen, P., 1921. Mecoptera. Monographic Revision. In: Collections zoologiques du baron Edm. de Selys Longchamps. Catalogue Systématique et Descriptif, vol. 5. Hayez. Bruxelles. 72 pp.

GBIF Secretariat, 2019. GBIF Backbone Taxonomy. Checklist dataset disponible en https://doi. org/10.15468/39omei (último acceso: 24 Jul. 2020).

Grimaldi, D. \& Engel, M. S., 2005. Evolution of the Insects. Cambridge University Press.

Hoffmann, J., 1966. Faune des Mécoptères du Grand-Duché de Luxembourg. Archives de l'Institut Grand-ducal de Luxembourg, 31: 105-159.

Izquierdo, I., Martín, C., París, M. \& Santos, C., 1997. La colección de Entomología del Museo Nacional de Ciencias Naturales (CSIC). Graellsia, 53: 49-85. https://doi. org/10.3989/graellsia.1997.v53.i0.365

Klug, F., 1836. Versuch einer systematischen Feststellung der Insekten-Familie: Panorpatae und Auseinandersetzung ihrer Gattungen und Arten. Abhandlungen der Königlichen Akademie der Wissenschaften zu Berlin, 1836: 81-108.

McLachlan, R., 1869. Synopsis of the species of Panorpa occurring in Europe and the adjoining countries, with a description of a singular new species from Java. Trans- actions Entomological Society of London, 17(1): 59-70. https://doi.org/10.1111/j.1365-2311.1869.tb01098.x

Miyake, T., 1908. A list of Panorpidae of Japan: with descriptions of ten new species. The Bulletin of the College of Agriculture, Tokyo Imperial University, 8: 1-12.

Monserrat, V. J. \& Tillier, P., 2013. Sinopsis de los mecópteros de la Península Ibérica (Insecta, Mecoptera). Boletín de la SEA, 53: 143-152. Disponible en http://sea-entomologia.org/PDF/Boletin53/143152BSEA53Mecopter aPen.pdf (último acceso: 24 Jul. 2020).

Navás, L., 1903. Neurópteros Prosostomios de la Península Ibérica. Brotéria 2: 107-113.

Navás, L., 1914. Insectes Névroptères I. Planipennia et Mecoptera. In: Voyage de Ch. Alluaud et R. Jeannel en Afrique orientale (1911-1912). Résultats scientifiques, 11. A. Schultz. Paris: 3-52. https://doi.org/10.5962/bhl. title. 152165

Novokshonov, V. G., 2004. The morphology, ecology, and classification of scorpionflies (Insecta, Mecoptera). Entomological Review, 84(2): 233-245.

Penny, N. D. \& Byers, G.W., 1979. A check-list of the Mecoptera of the World. Acta amazonica, 9(2): 365388. https://doi.org/10.1590/1809-43921979092365

Tillier, P., 2008. Contribution à l'étude des Mécoptères de France. Deuxième partie: clé de détermination des Panorpa de France (Mecoptera Panorpidae). L'Entomologiste, 64(1): 21-30.

Ward, P. H., 1979. Structural variation in the genitalia of the Panorpa alpina-complex (Mecoptera). Systematic Entomology, 4 (1): 71-79. https://doi. org/10.1111/j.1365-3113.1979.tb00612.x

Webb, D. W., Penny, N. D. \& Marlin, J. C., 1975. The Mecoptera, or scorpionflies, of Illinois. Illinois Natural History Survey Bulletin, 31(7): 268-282. https://doi. org/10.21900/j.inhs.v31.151

Whiting, M. F., 2002. Mecoptera is paraphyletic: multiple genes and phylogeny of Mecoptera and Siphonaptera. Zoologica scripta, 31(1): 93-104. https://doi. org/10.1046/j.0300-3256.2001.00095.x

Willmann, R., 1976. Zur Kenntnis der italienischen Mecoptera (Insecta). Bollettino del Museo civico di Storia naturale di Verona, 3: 157-177.

Willmann, R., 1987. The phylogenetic system of the Mecoptera. Systematic Entomology, 12(4): 519-524. https://doi.org/10.1111/j.1365-3113.1987.tb00222.x 